Estudios sobre armas antiguas, armamento, arte militar y vida cultural en oriente y occidente

XXVI (2006), pp. 119-147

ISSN: 0435-029X

\title{
EL INSTITUTO DE ESTUDIOS SOBRE ARMAS ANTIGUAS (CSIC). UNA APROXIMACIÓN A SU HISTORIA (1960-1998)
}

POR

\author{
ÓsCAR García VueLta*
}

\section{RESUMEN - ABSTRACT}

Se presenta una primera aproximación a la historia del antiguo Instituto de Estudios sobre Armas Antiguas, una institución vinculada al CSIC desde 1964, fundadora y editora de la Revista Gladius, y predecesora del actual Instituto Histórico Hoffmeyer (CSIC). Las aportaciones que se recogen en este trabajo permiten sistematizar sus principales avatares y períodos, así como estructurar un punto de partida para la elaboración de futuros estudios sobre la Institución y sus fundadores: Erling Ferdinand Hoffmeyer y Ada Bruhn de Hoffmeyer.

The aim of this article is to present a history of the former Instituto de Estudios sobre Armas Antiguas. This research centre was created by Ada Bruhn and E.F. Hoffmeyer in Denmark (1960), moved to Spain in 1962 and became linked to the Consejo Superior de Investigaciones Cientificas (CSIC) in 1965. The institute was the publisher of the international journal Gladius and predecessor of the current Instituto Histórico Hoffmeyer, that belongs to the CSIC. In these pages we explain the main activities and trace the evolution of the institution, giving a starting point for future research about the history of this centre and its founders.

\section{PALABRAS CLAVE - KEYWORDS}

Instituto de Estudios sobre Armas Antiguas; Instituto Histórico Hoffmeyer; Ada Bruhn; Erling Ferdinand Hoffmeyer; Gladius; Armología; Polemología.

Instituto de Estudios sobre Armas Antiguas; Instituto Histórico Hoffmeyer; Ada Bruhn de Hoffmeyer; Erling Ferdinand Hoffmeyer; Gladius; Armology; Polemology.

«El futuro es un gran problema». Ada Bruhn de Hoffmeyer Diario Hoy (Extremadura), 9 de mayo de 1988

\section{INTRODUCCIÓN}

El Instituto de Estudios sobre Armas Antiguas (IEAA), un centro de investigación autónomo vinculado al Consejo Superior de Investigaciones Científicas, constituyó desde principios de los años 60 hasta inicios de los 90 una institución de singular relevancia en los estudios sobre polemología y armas antiguas en España. Su creación y desarrollo son fruto de una singular historia que parte de la continuada y generosa labor de sus fundadores (Fig.1), el

\footnotetext{
* Instituto Histórico Hoffmeyer, Instituto de Historia (CSIC).
} 
matrimonio danés compuesto por el Bibliotecario Mayor Erling Ferdinand Hoffmeyer (19011975) y la investigadora y conservadora de museos Adelheid (Ada) Maria Bruhn de Hoffmeyer (1910-1991).

El IEAA fue fundado en el año 1960 en Kalundborg (Dinamarca), aunque fue trasladado a España a finales de 1962, contando a lo largo del tiempo con sedes en Madrid, Granada y Jaraíz de la Vera (Cáceres).

Entre las tareas desarrolladas desde el centro debe destacarse la edición de la revista Gladius, de reconocido prestigio internacional; la elaboración o edición de numerosos artículos y monografías científicas; la creación de una amplia biblioteca especializada; o una continuada labor de asesoría para investigadores y coleccionistas.

Después del fallecimiento de sus fundadores, el instituto fue legado al CSIC por voluntad testamentaria de Ada Bruhn de Hoffmeyer. Tras un período de cierre durante el cual se acometió la reforma y el acondicionamiento de sus instalaciones, la institución volvió a abrir sus puertas en Julio de 1997. En febrero de 1998 se constituyó el patronato del Instituto Histórico Hoffmeyer, dependiente del Instituto de Historia del CSIC (Cruz, 1998: 44), y en 1999 se reanudó la publicación de la revista Gladius. ${ }^{1}$

A pesar de la singularidad de esta institución, única durante años en su género (Soler, 1991 b: 8), han sido muy pocos los trabajos que hasta la fecha se han ocupado de la misma. De esta manera han permanecido en buena medida desconocidas para el investigador -dejando al margen las pocas referencias institucionales suministradas desde el centro- buena parte de su historia y avatares, junto a muchas de las circunstancias que condicionaron su evolución.

Esta situación se ha visto propiciada, entre otros factores, por la falta de una adecuada sistematización del extenso fondo documental reunido en el centro a lo largo del tiempo ${ }^{2}$. En ese sentido, desde finales de 2005, el Instituto Histórico Hoffmeyer ha comenzado la catalogación y puesta en valor de los archivos gráficos y documentales del antiguo IEAA. Aunque la mayor parte de las tareas desarrolladas hasta el momento se han centrado en el estudio y digitalización de su fototeca especializada, los trabajos también realizados en su archivo, junto a otras tareas de documentación y revisión bibliográfica, han permitido ya esbozar una visión más amplia sobre la institución.

A partir de estos datos, nuestro trabajo se plantea un doble objetivo; en primer lugar, presentar un repaso estructurado a la historia y los avatares del IEAA. En segundo lugar, ofrecer una información de partida básica sobre el centro y sus fundadores, importante para la elaboración de futuros estudios que a buen seguro permitirán analizar con más detalle muchas de las cuestiones aquí planteadas ${ }^{3}$.

1 En el Patronato del IHH están presentes el CSIC, la Junta de Extremadura (a través de su Consejería de Cultura y Patrimonio), la diputación de Cáceres, el Ayuntamiento de Jaraíz de la Vera, Patrimonio Nacional y la Caja de Ahorros de Extremadura.

2 Estructurado hasta 1975 por E. F. Hoffmeyer y posteriormente por Ada Bruhn; por desgracia, la organización original de este archivo se vio alterada durante el período de reformas de los años 90. En la actualidad la catalogación y estudio de estos fondos documentales -a los que hay que sumar el archivo personal del matrimonio Hoffmeyer- está aún en curso. Agradecemos a Lise Høj y Augusto Dreyer su ayuda en la traducción de diversos documentos y publicaciones de gran importancia para la elaboración de este trabajo. Agradecemos también a Marc Gener (Dpto. Prehistoria, IH, CSIC) su colaboración en la identificación y revisión general de estos fondos, así como sus acertados comentarios sobre el texto. Finalmente, agradecemos a Alvaro Soler del Campo (Real Armería, Madrid) sus valiosas observaciones sobre diferentes aspectos de la evolución del IEAA y la figura de sus fundadores.

3 Algunas de las cuales, como el análisis exhaustivo de las relaciones institucionales nacionales e internacionales del IEAA, el estudio detallado de las aportaciones científicas publicadas en Gladius; o el comentario pormenorizado de la actividad institucional del actual IHH serán tratadas superficialmente en estas páginas. 


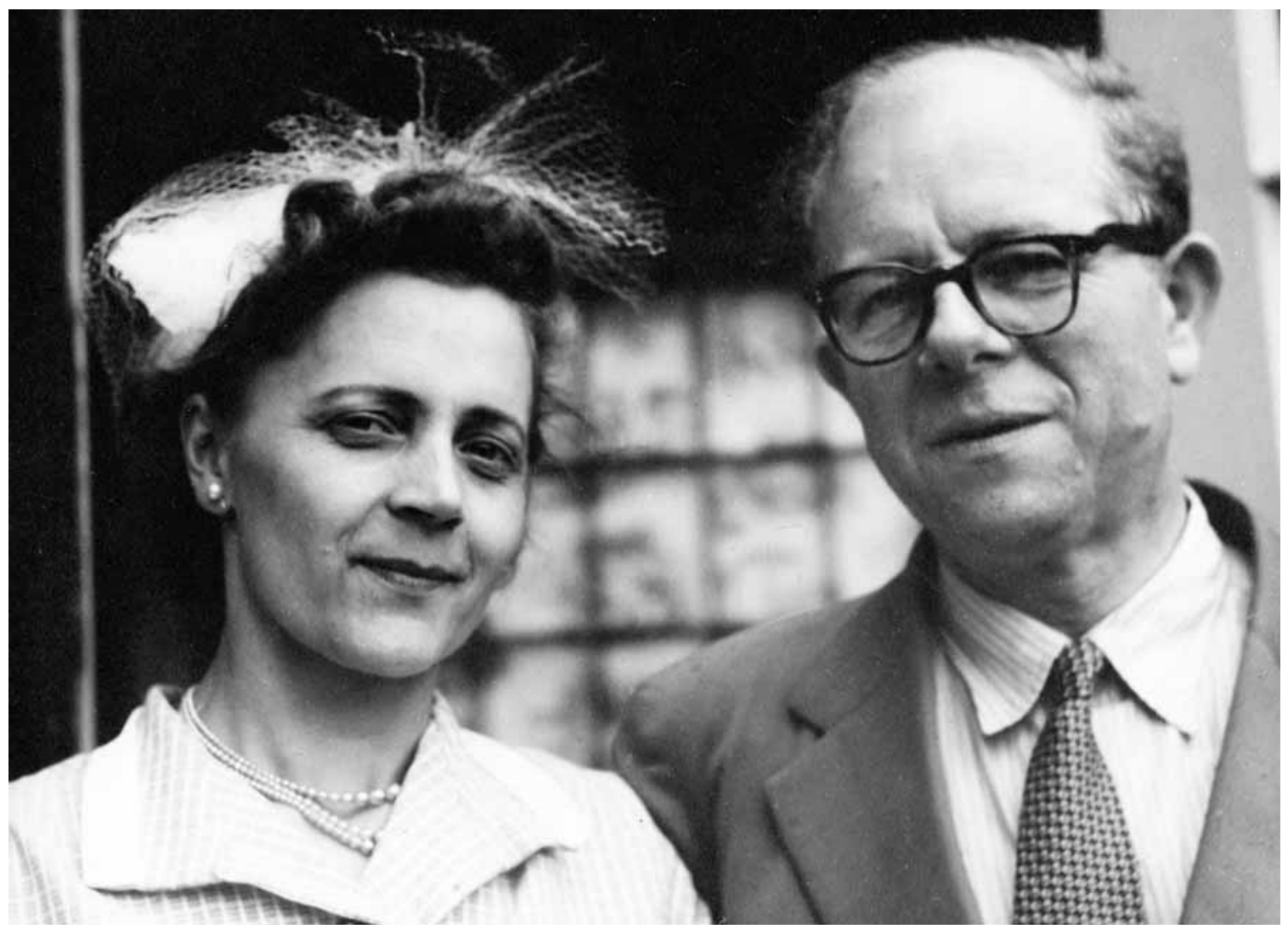

Fig. 1. El matrimonio Hoffmeyer, en 1951. Fototeca IHH. Colección Personal Hoffmeyer.

\section{El INSTITUTO Y SUS FUNDADORES}

El IEAA no puede ser desvinculado de la figura de los Hoffmeyer, que a lo largo del tiempo soportaron personalmente todo el peso de trabajo y las cargas económicas derivadas de una institución de esta naturaleza. El matrimonio fue igualmente responsable del mantenimiento de Gladius, editando los 17 primeros volúmenes de los 26 que actualmente componen su colección, así como diversas monografías.

Puede afirmarse que el planteamiento y la evolución del IEAA estuvieron unidos tanto a los intereses de investigación de los Hoffmeyer como a su profundo afecto por España, que fue incrementándose progresivamente tras su primera visita el país en julio de 1951. De dicho interés dieron cuenta los numerosos trabajos que publicarán desde principios de esta década (Hoffmeyer y Bruhn, 1952 o Hoffmeyer 1961), o sus frecuentes viajes de estudio hasta 1962, momento en que su residencia se trasladó definitivamente a España. A mediados de los años 60, los Hoffmeyer habían declarado ya su voluntad de donar la institución al estado español.

A lo anterior hay que sumar además al menos otros dos aspectos que también condicionaron la evolución del IEAA: los frecuentes problemas de salud del matrimonio y fundamentalmente su esfuerzo por encontrar una ubicación e instalación adecuadas para el instituto. Esta preocupación, resumida en la frase de Ada Bruhn con la que hemos iniciado este artículo, influirá decisivamente en la mayor parte de los avatares que el centro experimentó a lo largo de sus más de 30 años de actividad. 


\section{Erling Ferdinand (Fernando) Hoffmeyer}

Nació en Store Hedinge (Dinamarca) el 13 de marzo de 1901, en el seno de una familia dedicada al comercio afincada en Kalundborg desde 1905. Cursó bachillerato en la localidad de Høng, y realizó estudios de Filología en la Universidad de Copenhague, que amplió a lo largo del tiempo con estudios de Historia, Teología y Filología en varias instituciones y universidades europeas (Colaborador, 1975; Kay, 1975).

Hoffmeyer, que dominaba con soltura varias lenguas (entre otras el español, el griego antiguo y el hebreo) desarrolló su vida profesional como bibliotecario. Entre sus actividades previas a esa etapa hay que destacar sin embargo su colaboración entre 1928 y 1932 en la organización y elaboración del Catálogo de inscripciones rúnicas de Dinamarca, para el Museo Nacional de Copenhague. A partir de 1932, y tras obtener el correspondiente título por parte de la Academia de la Biblioteca de Dinamarca, Hoffmeyer trabajó en varias bibliotecas de este país, siendo nombrado en 1935 jefe del grupo de bibliotecas Söllerod, en las cercanías de Copenhague (Kay, 1975: 427; Colaborador, 1975: 8).

El 3 de julio de 1951 E. F. Hoffmeyer contrajo matrimonio con Ada Bruhn, realizando poco después un primer viaje por España que le marcará profundamente, y que dio como resultado la elaboración del libro-guía de viaje Spanien på kryds og tvaers: Råd og vink for spaniensrejsende $e^{4}$, que publicó junto a su esposa en 1952. Desde estos momentos y durante toda una década realizó diversos viajes a este país, aprovechando tanto excedencias laborales como períodos vacacionales. Cursó además estudios de Filología e Historia de España en la Universidad de Copenhague, y llegó a participar en 1956 en la elaboración de un conocido diccionario Español-Danés, junto a su profesor C. Bratli y el hispanista K. Kinzi (Colaborador, 1975: 8). ${ }^{5}$

A lo largo de sus estancias en España, E. F. Hoffmeyer se centró en sus estudios de historia (fundamentalmente sobre la época hispano musulmana), teología y filología, asistiendo a cursos en instituciones como el CSIC $^{6}$ o las Universidades de Salamanca y Madrid. Desarrolló también su trabajo en varios museos y centros como el Archivo de Simancas, la Biblioteca Nacional o el Instituto Valencia de Don Juan, entre otros. Todas estas actividades le permitieron entablar amistad con diferentes personalidades académicas, destacando por ejemplo la que mantuvo con el profesor Manuel García Blanco, en la Universidad de Salamanca, o con el sacerdote y arabista Pedro Longás, en el Instituto Valencia de Don Juan de Madrid (Colaborador, 1975: 8 y 10), entre otras.

En esta etapa, Hoffmeyer también llevó a cabo estudios en otras instituciones europeas, como la Biblioteca Apostólica Vaticana de Roma. Durante sus estancias en Dinamarca, elaboró diversas publicaciones y numerosos artículos de prensa de temática cultural variada, participando activamente en el apoyo a la docencia del español y el conocimiento de España en ese país.

Debido al cansancio y a problemas de salud, Hoffmeyer se jubiló en 1955 (Kay, 1975: 427) ${ }^{7}$. En 1960, fundó junto a Ada Bruhn el IEAA en Kalundborg, decidiendo poco después su traslado a España.

\footnotetext{
${ }^{4}$ Cuyo título podría traducirse como «Zigzag a través de España: consejos e indicaciones para los viajeros en España». El libro, firmado por Ada Bruhn y E. Ferdinand Hoffmeyer, fue publicado en Copenhague (Schultz). Como ya se ha señalado, se trató de una de las primeras obras favorables a España que fueron publicadas en Dinamarca durante esta época (Colaborador, 1975: 9).

5 Publicado en 1956 con el título Spansk-Dansk Ordbog en Copenhague (Gyldendal), contó con varias reediciones.

${ }^{6}$ La acreditación académica de E. F. Hoffmeyer se conserva aún en el Archivo del Centro de Humanidades (CSIC), subsección 2.1.1. Patronato «Marcelino Menéndez Pelayo. N. ${ }^{\circ} 1178$.

7 Poco tiempo después el matrimonio Hoffmeyer, de profundas convicciones religiosas, abandonó la religión protestante, convirtiéndose al catolicismo en agosto del año 1958.
} 


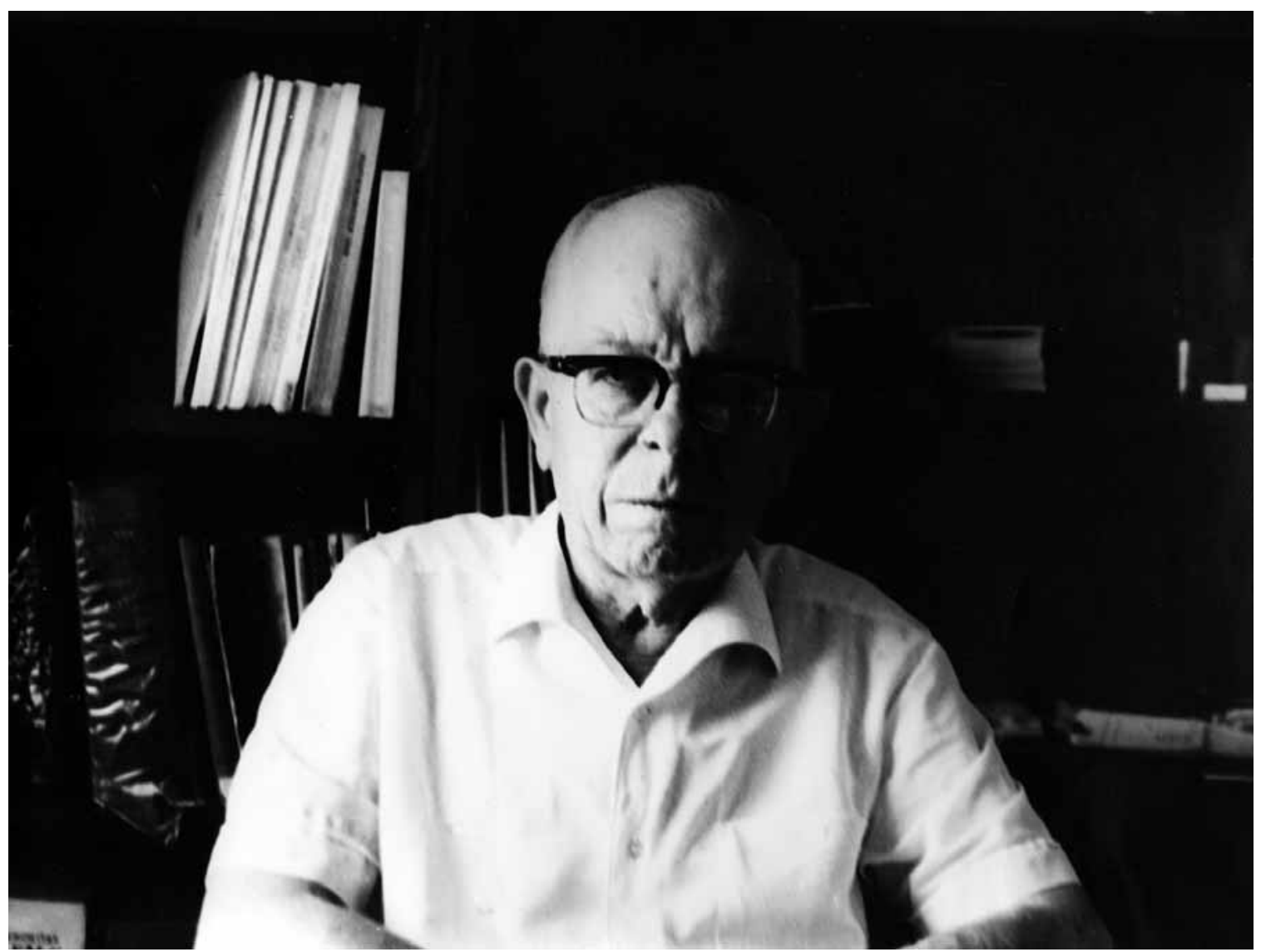

Fig. 2. Una de las últimas imágenes de E. F. Hoffmeyer, probablemente en las instalaciones del IEAA a principios de los años 70. Fototeca IHH. Colección Personal Hoffmeyer.

Aunque continuó trabajando en sus propios temas de estudio a partir de estos momentos (p. ej. Hoffmeyer 1961), sus actividades se fueron centrando progresivamente en la gestión del IEAA (Colaborador, 1975: 11). En Hoffmeyer recayó la mayor parte de las numerosas tareas burocráticas y de gestión del instituto y su publicación Gladius, lo que permitió a Ada Bruhn una mayor concentración en sus actividades de investigación (Cruz, 1998: 43). Apoyado en su larga experiencia laboral, Hoffmeyer asumió la responsabilidad de organizar la biblioteca, los archivos y las imágenes del IEAA ${ }^{8}$, supervisando personalmente todos los pormenores de su instalación. Para esta labor recurrió al castellano, utilizando como referencia para la catalogación de los originales el sistema de clasificación decimal universal (CDU).

Hasta sus últimos momentos, Hoffmeyer fue un sólido impulsor del centro y su publicación, a pesar de los numerosos problemas con los que tuvo que enfrentarse para mantenerlos, que acabaron por minar su salud, como ya se señaló en la sentida necrológica publicada en el volumen XII de Gladius, en el que el investigador se encontraba trabajando en sus últimos días (Colaborador, 1975: 7 y 11). El director del IEAA falleció en Plasencia, víctima de una

8 Tarea que inició durante la primera instalación del centro en Jaraíz de la Vera (1964-1966) y que llevó principalmente a cabo durante su estancia en Granada, entre 1966 y 1970 (Soler, 1991 b: 8), retomándola posteriormente tras su retorno a Jaraíz de la Vera, a principios de los años 70. El progresivo crecimiento de los fondos bibliográficos y documentales del IEAA obligó a Hoffmeyer a una constante actividad en este sentido (IEAA, 1973: 122; Hoffmeyer, 1974: 139; Soler, 1991 b: 8). 
dolencia cardiaca, la noche del 2 de abril de 1975 y fue enterrado en la localidad de Jarandilla de la Vera (Cáceres).

E. F. Hoffmeyer formó parte de diversas asociaciones. En Dinamarca puede citarse por ejemplo su pertenencia a la Historik-Topografisk Selskab for Scollerod Kommune o al citado Sollerod Biblioteksforening (Kay, 1975: 147). Ya en España, hay que señalar entre otras distinciones sus nombramientos como Caballero del Monasterio de Yuste en 1964, y como Correspondiente del Museo del Ejército en octubre de 1973, junto a su esposa (Hoffmeyer, 1974: 141; Colaborador, 1975: 12).

\section{Adelheid (Ada) Maria Bruhn de Hoffmeyer}

Nació en Roskilde (Dinamarca) el 1 de diciembre de 1910 siendo, según sus propias palabras, una gran apasionada de la arqueología ya desde la niñez (Bruhn, 1953: 51 y ss). Tras finalizar su bachillerato en el instituto de Roskilde en 1929 inició sus estudios de Arqueología Clásica en la Universidad de Copenhague, donde recibió un gran apoyo de su profesor K. Johansen (Bruhn 1953: 59). Se graduó con el título de Magister Artrium en 1936 (Kay, 1974: 245; Øgsbro, 2003) con una tesina sobre vasos griegos titulada Oltos and Early red-figure vase Painting (Bruhn, 1943; Soler, 1991 b: 8).

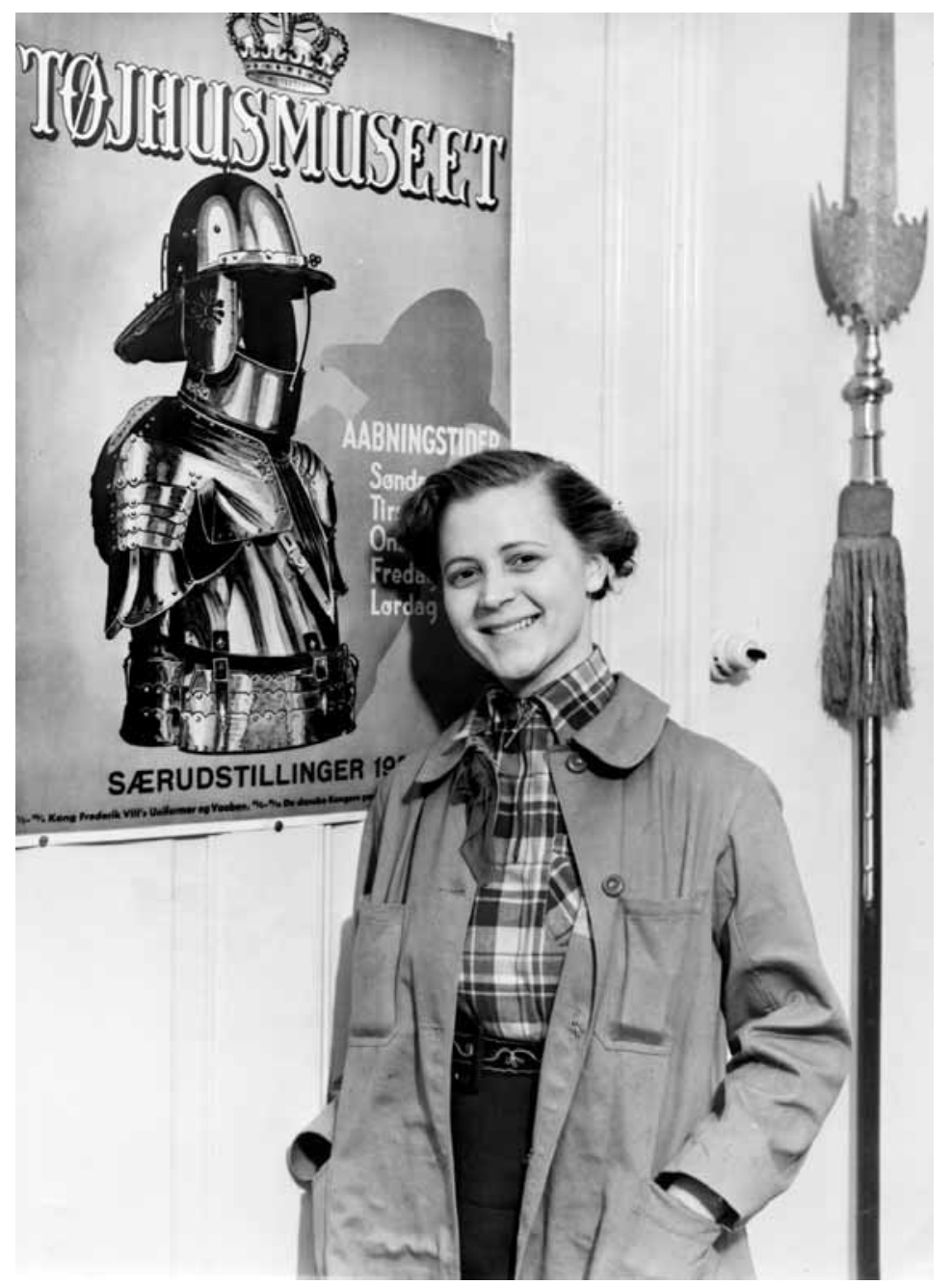

Fig. 3. Ada Bruhn durante su primera etapa en el Tohjusmuseet, probablemente en 1939. Fototeca IHH. Colección Personal Hoffmeyer. 
En 1934, y tras desempeñar otros trabajos (Bruhn, 1955: 145), Ada Bruhn obtuvo un puesto como asistente de museo en la Ny Carlsberg Glyptotek de Copenhague -bajo la dirección de Frederik Poulsens-, que mantuvo hasta 1939 y que simultaneó durante un tiempo con sus estudios universitarios (Bruhn, 1953: 59 y 60). En este período y gracias a varias ayudas, realizó algunos viajes por Europa orientados fundamentalmente a la investigación de la cerámica griega y la cultura clásica, que fueron fundamentales en la elaboración de algunos de sus trabajos posteriores (Bruhn, 1943; Bruhn y Hjorts $\varnothing, 1948$ o Bruhn et alii, 1966, entre otros). En 1935 la investigadora había efectuado ya un viaje de estudio a Inglaterra, con estancias en el British Museum o los Museos de Oxford y Cambrigde (Bruhn, 1953: 60 y 61). En esta misma etapa visitó también Alemania, Francia, Bélgica y Holanda, destacando su estancia de medio año -financiada por la Ny Carlsbergfondet- en el Instituto Sueco de Arqueología en Roma, en 1937 (Bruhn, 1943: 7; 1953: 61; Kay, 1974: 245; Soler, 1991 b: 8; Cruz, 1998: 42).

A primeros de octubre de 1939, Ada Bruhn pasó a desempeñar el cargo de Asistente de Museo y Biblioteca en la Armería Real de Copenhague (Tojhusmusseet), iniciándose en estos momentos su interés en el campo del armamento antiguo (Bruhn, 1953: 61 a 63; VV.AA, 1988: 364). En 1942 fue nombrada conservadora y jefe del Departamento de Armas Blancas y Armaduras de este museo, permaneciendo en el cargo hasta 1959.

Durante este período desarrolló una intensa actividad profesional y de investigación, centrada en la arqueología de las armas antiguas, especialmente en la etapa medieval. Principalmente desde 1946 realizó varios viajes relacionados con su actividad en el Tojhusmusseet y la preparación de su tesis doctoral, financiados por la Carlsbergfondet, Ny Carlsbergfondet y el gobierno danés (Bruhn, 1953: 63-64; Bruhn 1955: 146). En 1948 recibió de la American Association of University Women la beca Aurelia Henry Reinhardt, disfrutando de una estancia de medio año en EE.UU para el estudio de museos y colecciones (Bruhn, 1953: 64). En 1951 obtuvo de la Ny Carlsbergfondet la beca Carls Jacobsen Museumsmandslegat, que dedicó a estudios en Francia, España y Portugal, realizando una posterior estancia en España e Italia en 1953 (Bruhn, 1955: 146). En noviembre de 1954 consiguió finalmente el doctorado por la universidad de Copenhague, con su estudio tipológico y cronológico sobre las espadas medievales Middelalderens Tveaeggede Svaerd (Bruhn, 1954).

Fig. 4. Ada Bruhn durante sus años como conservadora del Tohjusmuseet, probablemente a principios de los años 50. Fototeca del IHH. Colección Personal Hoffmeyer.

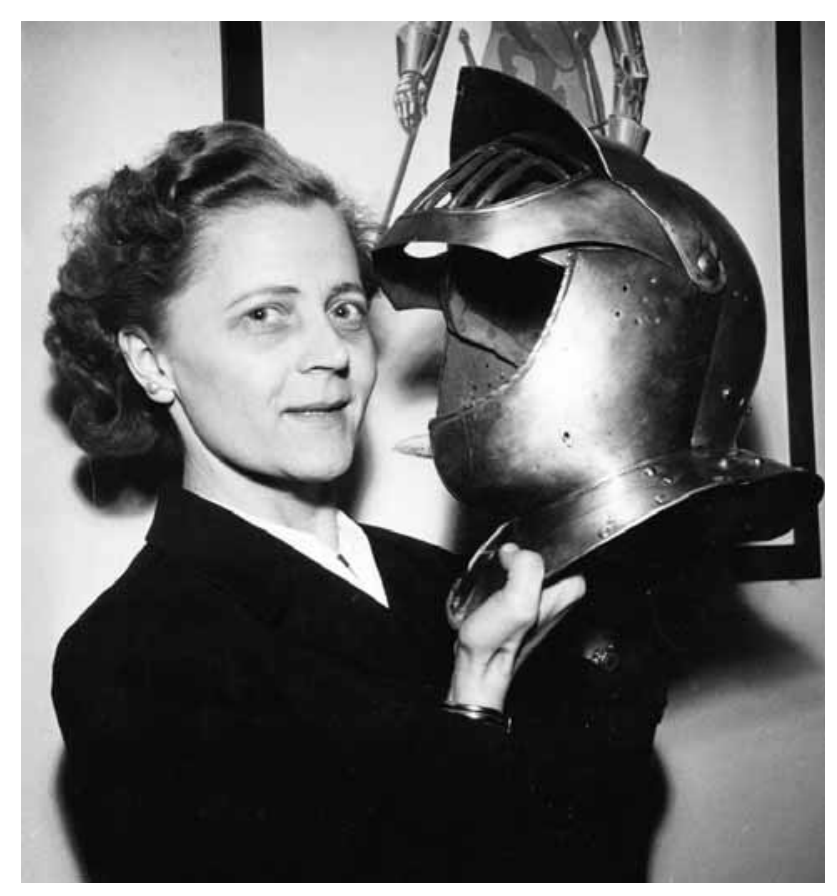


A lo largo de estos años, Ada Bruhn combinó su trabajo de investigación con una activa labor en el Tohjusmuseet. Influida por la experiencia de sus numerosos viajes -principalmente su estancia en los EE.UU- fue una decidida impulsora de la renovación didáctica en el museo, impulsando por ejemplo el desarrollo de exposiciones y actividades específicamente diseñadas para los niños. Tampoco disminuyó su interés por la Península Ibérica tras la lectura de su tesis doctoral, realizando diversos viajes a lo largo de los años 50, a menudo en compañía de E. F. Hoffmeyer. En ese sentido, pueden destacarse por ejemplo sus estancias en la universidad de Salamanca, entre 1956 y 1958 (Kay, 1974: 245).

Ada Bruhn llegó a alcanzar una gran popularidad en Dinamarca, tanto por su condición de mujer dedicada a este especializado campo de la investigación como por sus actividades en el Tohjusmuseet. Especialmente durante los años 50 fue protagonista de numerosos artículos de prensa ${ }^{9}$, quedando incluida en varias obras dedicadas a personajes destacados de su país (Bruhn, 1953). A lo largo de esta etapa, y aparte de realizar numerosas aportaciones científicas, participó además en diferentes asociaciones de mujeres danesas (Øgsbro, 2003) siendo una decidida impulsora de la igualdad de género. La investigadora colaboró también habitualmente en periódicos, no sólo con apuntes de divulgación arqueológica, sino también con diversos escritos sobre sus actividades en el Tohjusmuseet, el papel de la mujer en la sociedad, aspectos de la cultura española, etc.

Desde mediados de la década de los 50, sin embargo, sus relaciones laborales se vieron muy afectadas a raíz de un largo período de enfrentamientos con la dirección del Tohjusmuseet. Dicha confrontación, en la que participó junto a otros miembros de esta institución y que tuvo una notable repercusión en Dinamarca, motivó graves problemas laborales y de salud a Ada Bruhn, influyendo decisivamente en su retiro anticipado -tras un largo período de baja médica- a mediados de 1959 (Øgsbro, 2003) ${ }^{10}$. Un año después, creó junto a E. F. Hoffmeyer el Instituto de Estudios sobre Armas antiguas y la revista Gladius, que trasladaron a España en 1962, ocupando en solitario tanto la dirección del centro como la de su publicación tras la muerte de su esposo.

Ada Bruhn falleció en Plasencia, el día 24 de Julio de 1991, habiendo legado previamente el IEAA al Consejo Superior de Investigaciones Científicas ${ }^{11}$; tanto sus actividades de inves-

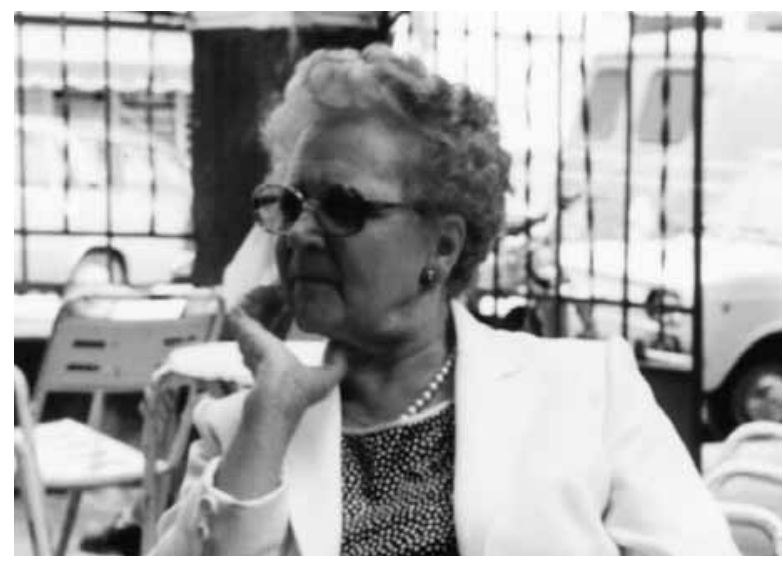

Fig. 5. Ada Bruhn a mediados de los años 80 en Jaraíz de la Vera. Original en Fototeca IHH. Colección personal Hoffmeyer. tigación como su gran preocupación y su lucha por el futuro del centro continuaron hasta sus últimos años (Cruz, 1998: 45; Soler, 1991 b: 8 y 9). La investigadora fue enterrada junto a su marido en la localidad de Jarandilla de la Vera.

Como se ha señalado, Ada Bruhn fue autora de numeras monografías y artículos científicos, en su mayor parte centrados en los campos de la Antigüedad Clásica -principalmente escultura y cerámica griega- y en el estudio de las armas antiguas -fundamentalmente armas blancas y armamento medieval- participando también en varias obras de referencia y catálogos especializados. Pueden destacarse por ejemplo sus colaboraciones en el Kultur-

9 Muchos de los cuales se conservan en el archivo del IEAA.

10 Diversas noticias sobre el retiro de Ada Bruhn aparecieron en la prensa danesa entre los meses de junio y julio de 1959. Archivo IEAA. Sección Prensa. Carpeta 1, n. ${ }^{\circ} 291$, entre otros.

11 Por voluntad testamentaria redactada el día 7 de marzo de 1989. 
historisk Leksikon for Nordisk Middelalder (1956), o en la edición española del Glossarium Armorum (1981) ${ }^{12}$. De su trabajos más representativos en el campo de la Arqueología Clásica hay que destacar, entre otros, su Oltos and Early red-figure vase Painting (1943); y ya en el campo del armamento su tesis doctoral Middelalderens tbeaggede Svaerd (1954), las obras Antikens Artillery (1958); Christensens Våbensamling (1968) ${ }^{13}$; o la conocida Arms and Armour in Spain Vol. I (1972) y Vol. II (1982), aún de obligada referencia para el estudio de las armas medievales peninsulares, junto a otros títulos (p.ej. Bruhn, 1965) (Soler, 1991 b: 9). De sus trabajos en Gladius, y junto a numerosas reseñas y comentarios, los artículos «Introduction to the history of the European sword» (1961); «From mediaeval sword to Renaissance rapier» (1963) y «Military equipment in the Byzantine manuscript of Scylitzes in Biblioteca Nacional in Madrid» (1965). Entre sus últimos estudios, el trabajo también aparecido en Gladius «Las armas de los conquistadores. Las armas de los Aztecas» (1986), o el publicado en las actas de Simposio Las armas en la Historia (IEAA - Univ. de Extremadura) «Las armas en la historia de la reconquista» (1988).

Ada Bruhn perteneció a diferentes asociaciones sobre armas antiguas, entre las que pueden destacarse The Arms \& Armour Society de Londres - de la que fue medalla de honor en 1984-; Gesellschaft für Historische Waffen und Konstumkunde, de Berlín; la Association Suisse pour l'Étude des Armes et Armures, de Ginebra; o la Academia de San Marciano, de Turín. En España cabe destacar su ya comentado nombramiento junto a E.F. Hoffmeyer como Correspondiente del Museo del Ejército en 1973 (Hoffmeyer, 1974: 141) o su distinción como Socia de Honor de la Asociación Española de Arqueología Medieval, en 1987 (Soler, 1991 b: 8).

\section{Historia y AVATARES DEL IEAA}

\subsection{Fundación y estancia en Kalundborg, Dinamarca (1960-1962)}

En palabras del propio matrimonio, el Instituto de Estudios sobre Armas Antiguas nació con el objetivo de «crear un centro de investigaciones científicas sobre la armología, el estudio de la arqueología, etnografía e historia de las armas antiguas, su estado y desarrollo en las civilizaciones orientales y occidentales (particularmente en el Oriente Próximo y más allá) así como sus relaciones y mutuas dependencias». Estas ideas, que fueron apuntadas en numerosas ocasiones, se mantuvieron inalteradas a lo largo del tiempo (IEAA 1973: 120 o Bruhn, 1985).

Las primeras gestiones para la creación del instituto comenzaron muy probablemente en Copenhague de una forma previa al retiro de Ada Bruhn. Ya en marzo de 1959, el matrimonio había declarado que quería abandonar esa ciudad para vivir una vida tranquila y dedicada a sus estudios ${ }^{14}$. En ese sentido, mantuvieron a finales del mes de julio algunas reuniones de trabajo con el investigador Abd-el-Rahman Zaky, conocido experto en armas, filología y heráldica orientales, que colaborará posteriormente en la fundación de Gladius.

Según la prensa danesa, que se hará eco de la fundación del centro, la familia de E. F. Hoffmeyer había informado por aquellos momentos al matrimonio de la disponibilidad de una casa histórica en Kalundborg, al Oeste de Copenhague, que podría servir para desarrollar su pro-

12 Junto a Javier Cortés.

13 Våbenhistoriske Aarborger, 1968. Copenhague.

14 A principios de los años 60, Ada Bruhn manifestó igualmente su deseo de concentrarse definitivamente en los estudios sobre armas tras el largo periodo de enfrentamientos en el Tohjusmuseet, así como de crear una publicación especializada en estas materias (Archivo IEAA. Sección Prensa. Carpeta 1. 309). 


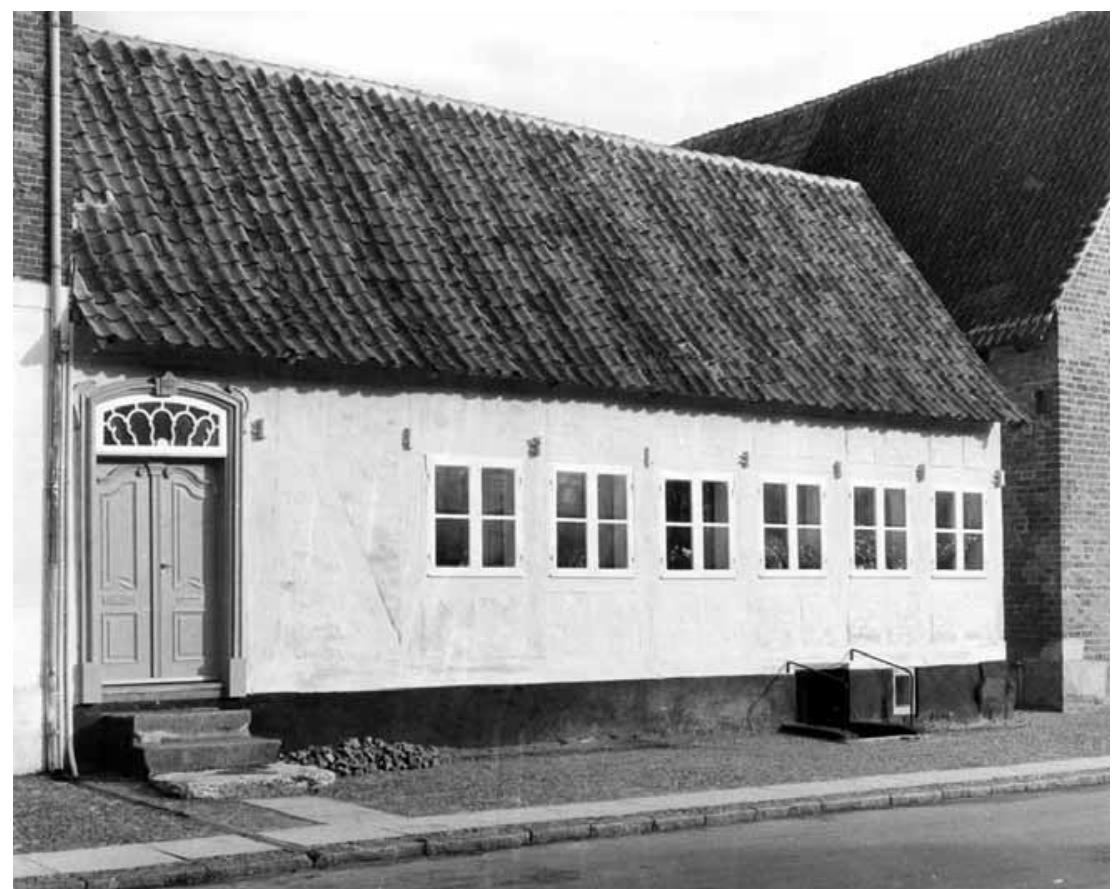

Fig. 6. Detalle de la fachada de la primera sede del IEAA (Adelgade n. ${ }^{\circ}$ 10, Kalundborg), tomada en 1960. Fototeca IHH. Colección Catalogada. Sección Generalidades. Reg. 2170. Foto: Lefolii. yecto. Interesados por dicho inmueble, de 300 años de antigüedad y bajo tutela del Museo Nacional de Dinamarca, los Hoffmeyer iniciaron laboriosas gestiones con el ayuntamiento de Kalundborg y el estado danés para ocupar y restaurar el edificio, emplazado en la calle Adelgade n. ${ }^{\circ} 10$ de la localidad (Fig. 6).

El matrimonio abandonó su domicilio en Genfofte (Copenhague) en febrero de 1960, trasladándose temporalmente a un hotel de Kalundborg. Sin embargo, y debido a varias complicaciones, la costo-

sa restauración de Adelgade 10 no finalizará hasta agosto de ese año. Entre tanto el matrimonio realizó un nuevo viaje por el sur de España, que se prolongó durante aproximadamente dos meses $^{15}$.

Finalmente, en agosto de 1960 los Hoffmeyer consiguen establecerse en Adelgade 10, donde fundan el IEAA, anunciando ya por las mismas fechas la preparación de Gladius $^{16}$. En la nueva residencia quedaron instalados la biblioteca, las fotografías y los archivos personales del matrimonio, que constituirán el núcleo de las futuras colecciones de la institución (Fig. 7).

La principal línea de actuación del IEAA en esta primera etapa, que se prolongó algo más de dos años, fue la creación y edición de Gladius, cuyo primer número apareció en 1961 (Fig. $8)^{17}$. El volumen inaugural de la revista contó como administrador con E. F. Hoffmeyer, y tuvo como redactores a Ada Bruhn y A. Zaky, encargándose los tres autores de todos los estudios incluidos en el ejemplar.

Durante su estancia en Kalundborg el matrimonio desarrolló además una gran actividad individual, que implicó tanto Ada Bruhn como E. F. Hoffmeyer en diversos trabajos científicos y numerosas colaboraciones de prensa, continuando además Hoffmeyer su labor como docente de español. Sin embargo, y a pesar de la buena marcha del proyecto del instituto y de la buena acogida con la que contó su revista, pronto comenzó a valorarse la posibilidad de instalar el centro en un lugar más apropiado para sus expectativas de proyección. El matri-

15 Archivo IEAA. Sección prensa. Carpeta 1. 297 y 298.

16 Archivo IEAA. Sección prensa. Carpeta 1. 306-310, 337.

17 Que figura con el subtítulo. «Revue Internationale des Études sur l'armes anciennes, L'Art Militaire et la Vie Culturelle en Orient et en Occident». El primer volumen de Gladius fue impreso en la pequeña imprenta Finns, en Ruds Veldby (Dinamarca), la noticia de la aparición de la revista, al igual que la del propio IEAA, fue recogida por la prensa danesa. Archivo IEAA. Sección Prensa. Carpeta 1, 310 entre otros. 


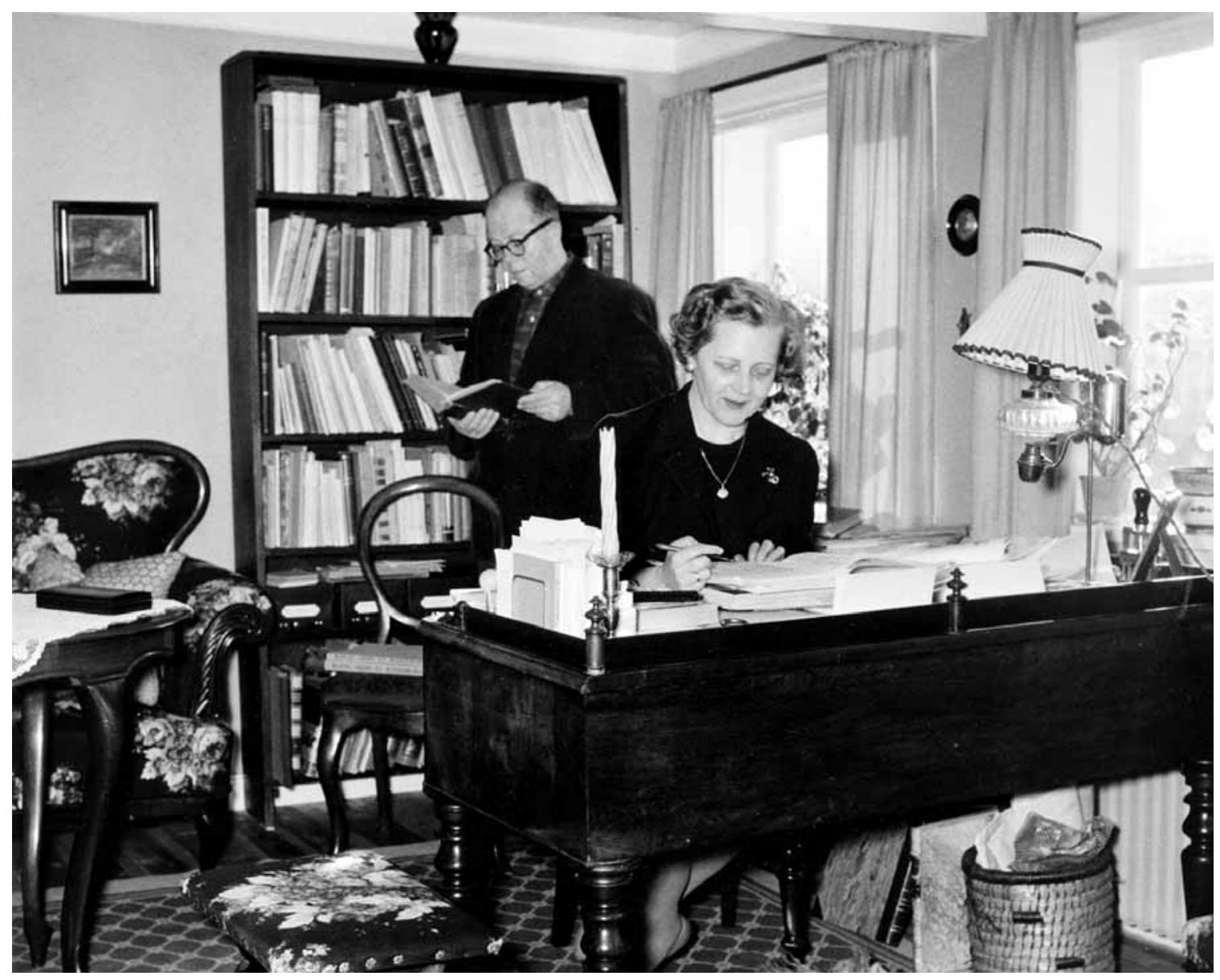

Fig. 7. Ada Bruhn y E. F. Hoffmeyer en las dependencias del IEAA en Kalundborg, en 1960. Fototeca IHH. Colección catalogada. Sección Generalidades. Reg. 2171. Foto: Lefolii.

monio se decidió por trasladar el IEAA a España ${ }^{18}$, influido principalmente por sus intereses de estudio, aunque también por el clima español -beneficioso para su delicada salud- y sus contactos con destacadas personalidades de este país ${ }^{19}$.

Hasta el momento, la información disponible sobre los últimos meses del IEAA en Dinamarca es escasa. Según las noticias recogidas por la prensa local, los Hoffmeyer habrían valorado inicialmente un cambio temporal de residencia, manifestando su intención de establecerse en la región de Córdoba. Según estas mismas referencias, los preparativos para el viaje y la venta de Adelgade 10 habían comenzado en octubre de 1962, aunque el traslado del centro no se produjo hasta principios de noviembre. De forma previa, Ada Bruhn había obtenido

18 «A partir del año 1951 hicimos varios viajes por España para hacer investigaciones científicas en bibliotecas, Archivos y Museos. Poco a poco reconocíamos que España, como el lazo de unión entre las culturas de Oriente y Occidente, así como promotora de nuevos impulsos, sería el sitio más adecuado para colocar un instituto de esta clase. En 1962 nos decidimos a trasladar el Instituto y la publicación GLADIUS a España». Carta dirigida el 4/9/1967 al Dir. Gral. de Bellas Artes para ofrecer la donación del Instituto al Estado. Archivo IEAA. Sección Asuntos Especiales.

19 Puede destacarse, por ejemplo, la amistad del matrimonio con el embajador español en Dinamarca, el Conde de Morales. 


\section{G L A D I U S}

REVUE INTERNATIONALE DES ETUDES SUR L'ARMES ANCIENNES,

L'ART MILITAIRE ET LA VIE CULTURELLE

EN ORIENT ET OCCIDENT

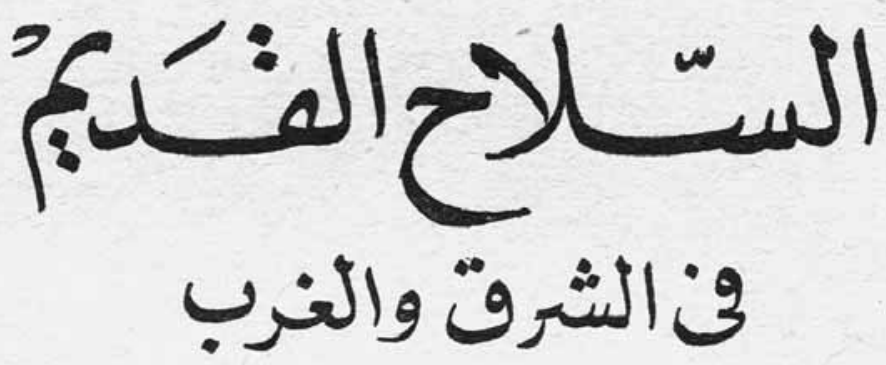

TOME 1

GLADIUS

1961

Fig. 8. Portada del primer número de Gladius, publicado en 1961. 
una ayuda de la Ny Calsbergfondet para sus estudios sobre armamento medieval, por un período de tres años ${ }^{20}$.

Sin embargo, a tenor de la correspondencia mantenida por los Hoffmeyer podría deducirse que el viaje se produjo en fechas anteriores, o que el matrimonio pudo disfrutar de una estancia previa en España poco antes de su traslado definitivo ${ }^{21}$.

\subsection{Traslado a España, viajes por el Sur del país y residencia en Madrid (1962-1963)}

Hasta donde sabemos, el desplazamiento a España de los Hoffmeyer no implicó en estos momentos la mudanza de la totalidad de las instalaciones del IEAA, quedando temporalmente en Dinamarca al menos parte de sus muebles y biblioteca ${ }^{22}$. Durante el mes de noviembre de 1962, el matrimonio realizó diversos viajes por el Sur de España, con estancias vacacionales y de estudio en Córdoba, Granada, Castell de Ferro, Motril o Antequera, entre otros lugares ${ }^{23}$.

A finales de enero de 1963 se inicia finalmente la que podemos denominar como una segunda fase de actividad del instituto, estableciéndose el matrimonio en la Residencia de Estudiantes del CSIC, en Madrid (C/ Pinar n. $\left.{ }^{\circ} 15\right)^{24}$. En este período, los Hoffmeyer emprendieron estudios en bibliotecas y museos de la capital, y reanudaron la actividad de su revista, cuya distribución fue encargada a la casa Insula (Gilbert, 1967: 303). El segundo volumen de Gladius, que aparece en 1963, incorporó una variación en su subtítulo-Etudes sur les armes anciennes, L'Armement; L'Art militaire et la vie culturelle en Orient et en Occident-, así como una significativa variación en sus créditos, figurando como directores Ada Bruhn y E. F. Hoffmeyer ${ }^{25}$.

La estancia en Madrid de los Hoffmeyer fue sin embargo corta. Desde su llegada, el matrimonio había aprovechado también su estancia en la Residencia para efectuar viajes relacionados con la búsqueda de un emplazamiento para el IEAA, manteniendo igualmente distintos contactos institucionales en ese sentido durante 1963. A finales de este año, y siguien-

20 Archivo IEAA. Sección Prensa. Carpeta 1. núms. 339, 343-347.

21 En la correspondencia mantenida desde febrero de 1962 parece apuntarse que el matrimonio preparaba un viaje a España para marzo de 1962: «Dentro de un mes saldremos para España... Esta vez viajamos en nuestro coche teniendo interés en visitar lugares de España cuyas comunicaciones son difíciles. Por ahora no sabemos cuando lleguemos [sic] a Madrid. Probablemente vayamos en primer lugar a la costa del sol para recrearnos, lo que necesitamos muchísimo después de un invierno nórdico con mucho trabajo. Mas tarde vamos a Madrid». Archivo IEAA. Sección Correspondencia. Carpeta «L». Carta de E. F. Hoffmeyer a Pedro Longás, 10/2/1962.

22 Como se deduce de la correspondencia con el conservador de la Real Armería de Madrid, Javier Cortés, en junio de 1964: «...hemos recibido nuestros muebles, la biblioteca y demás efectos desde Dinamarca. Ha sido un gran trabajo arreglar todo». Archivo IEAA. Sección Correspondencia. Carpeta «A».

${ }_{23}$ El matrimonio pudo adquirir por estas fechas la finca «El Tejar», en Benamejí (Córdoba), que venderá posteriormente para poder financiar el traslado del IEAA a Granada. Ya desde finales de 1962 los Hoffmeyer habían expresado también la voluntad de establecer su residencia en Granada, intentando por esos momentos adquirir una finca en las proximidades de dicha ciudad - probablemente la misma que ocuparán años después- (Archivo IEAA. Sección Correspondencia. Carpeta «A». Correspondencia con J. Antelo entre diciembre de 1962 y marzo de 1963). Algunos detalles de las actividades del matrimonio durante sus viajes pueden encontrarse también en su correspondencia con Pedro Longás en noviembre de 1962 (Archivo IEAA. Sección Correspondencia. Carpeta «L»).

${ }^{24}$ La primera referencia de ingreso de los Hoffmeyer en la Residencia desde su traslado -a nombre de E. F. Hoffmeyer-, data del 25/1/1963, figurando como procedente de Antequera, como se confirma en la ya citada correspondencia con P. Longás. Los Hoffmeyer residieron la mayor parte de 1963 en la habitación n. ${ }^{\circ} 15$ de la Residencia. En los libros de registro de la Institución de 1963, y hasta enero de 1964, se documentan varios viajes de estudio del matrimonio. Agradecemos al Archivo de la Residencia de Estudiantes las facilidades prestadas para la consulta de estos documentos.

25 El tercer volumen de Gladius, correspondiente al año 1964, será también editado desde Madrid por Insu$l a$, aunque figurando ya en este volumen la dirección del IEAA en la localidad de Jaraíz de la Vera. 
do al parecer «el consejo de unos amigos extremeños», el matrimonio se encontraba ya preparando su traslado a la localidad de Jaraíz de la Vera (Cáceres), donde quedó establecida la primera sede estable del instituto en España.

Probablemente, influyeron significativamente en esta decisión el clima de esta región, beneficioso para la salud de E. F. Hoffmeyer (Sánchez Ocaña, 1988) y el hecho de no haber podido culminar las tentativas previas para instalar el centro en Granada ${ }^{26}$. A principios de 1964, y después de haber realizado al menos un viaje a Extremadura, se registra el último paso del matrimonio por la Residencia de Estudiantes durante este período, abandonando la institución con destino a Jaraíz de la Vera el día 16 de enero ${ }^{27}$.

\subsection{Primera estancia del IEAA en Jaraíz de la Vera (1964-1966)}

De forma previa a su viaje, el matrimonio había mantenido contactos con el Ayuntamiento de Jaraíz de la Vera a través de su alcalde Albino Fernández ${ }^{28}$, que colaboró con los Hoffmeyer en la búsqueda de una residencia adecuada en la localidad. El IEAA quedó instalado en el conocido como «Barrio de San Isidro» de Jaraíz, ocupando dos casas contiguas recientemente construidas en la calle Obispo Manzano (núms. 30 y 32). Como será habitual en todas las ubicaciones posteriores del instituto estos edificios sirvieron a la vez, tras una conveniente reforma, como sede del centro y residencia del matrimonio, contando además con espacios destinados a alojar a visitantes e investigadores ${ }^{29}$.

Según el testimonio de los Hoffmeyer, esta primera etapa en Jaraíz constituyó un período de poca actividad, debido entre otras causas a problemas de salud y a las complicaciones propias del traslado y posterior montaje e instalación del mobiliario, biblioteca y otros objetos del centro (que no finalizó probablemente hasta mediados de junio de 1964). También influyeron en esta situación las diferentes dificultades de convivencia en la localidad surgidas durante este período ${ }^{30}$.

Sin embargo, y a pesar de estos retrasos, el trabajo en Gladius continuó tras la publicación desde Madrid de su tomo III (1964), como evidencia la preparación en Jaraíz del volumen IV (1965), que será posteriormente publicado desde Granada y aumentado con más páginas e ilustraciones ${ }^{31}$.

26 Que quedaron documentadas, por ejemplo, en la correspondencia mantenida entre enero y febrero de 1963 con J. Antelo, agente inmobiliario de Granada (Archivo IEAA. Sección Correspondencia. Carpeta «A»).

27 Archivo Residencia de Estudiantes. Libro de Salidas con título «Junio 1963»: 29.

28 Parte de la correspondencia relativa a estas gestiones, de principios y mediados de enero de 1964 se conserva en el archivo documental del IEAA (Sección Correspondencia. Carpeta «A»).

29 «Ocupamos dos casas: vivimos en una de ellas y en la otra hay almacén de libros, etc. y arriba dos habitaciones independientes con mesa de trabajo para huéspedes» (Archivo IEAA. Correspondencia. Caja «A». Carta dirigida a J. Cortés el 19/6/1964. La casa dedicada a biblioteca y almacén fue el actual n. ${ }^{\circ}$ 32, según nos informaron amablemente sus actuales propietarios.

30 De éstas, a las que hay que sumar serios problemas en la correspondencia del Instituto, se dio cumplida cuenta en la correspondencia del matrimonio (Entre otra, la mantenida con el párroco y amigo personal de los Hoffmeyer Valentín Soria, de Jarandilla de la Vera, en Julio de 1965 (Archivo IEAA. Correspondencia. Carpeta «L»), y en sus gestiones oficiales para buscar otro emplazamiento para el centro (p. ej. Archivo IEAA. Sección Asuntos Especiales. Carpeta 13. Carta a la dirección Gral. de Bellas Artes, 17/7/1965). Agradecemos a V. Soria sus informaciones en este sentido.

31 Los Hoffmeyer refieren además la falta de tranquilidad y el ruido existente en la barriada como una de las razones principales que limitaron sus actividades de investigación durante este período: «Mi esposa no ha podido terminar su trabajo sobre las armas bizantinas en el manuscrito de Scylitzes en la Biblioteca Nacional y yo casi no he trabajado durante nuestra estancia en Jaraiz. En lugar del artículo de mi esposa hemos tenido que procurar artículos del extranjero para el tomo IV de GLADIUS, que ha salido hace pocos días». Archivo IEAA. Correspondencia. Carpeta «A». Carta de E. F. Hoffmeyer a Felipe Jiménez, de Cuacos de Yuste, 2/3 /1966 (el trabajo de Ada Bruhn al que se refiere Hoffmeyer fue publicado en Gladius V). 


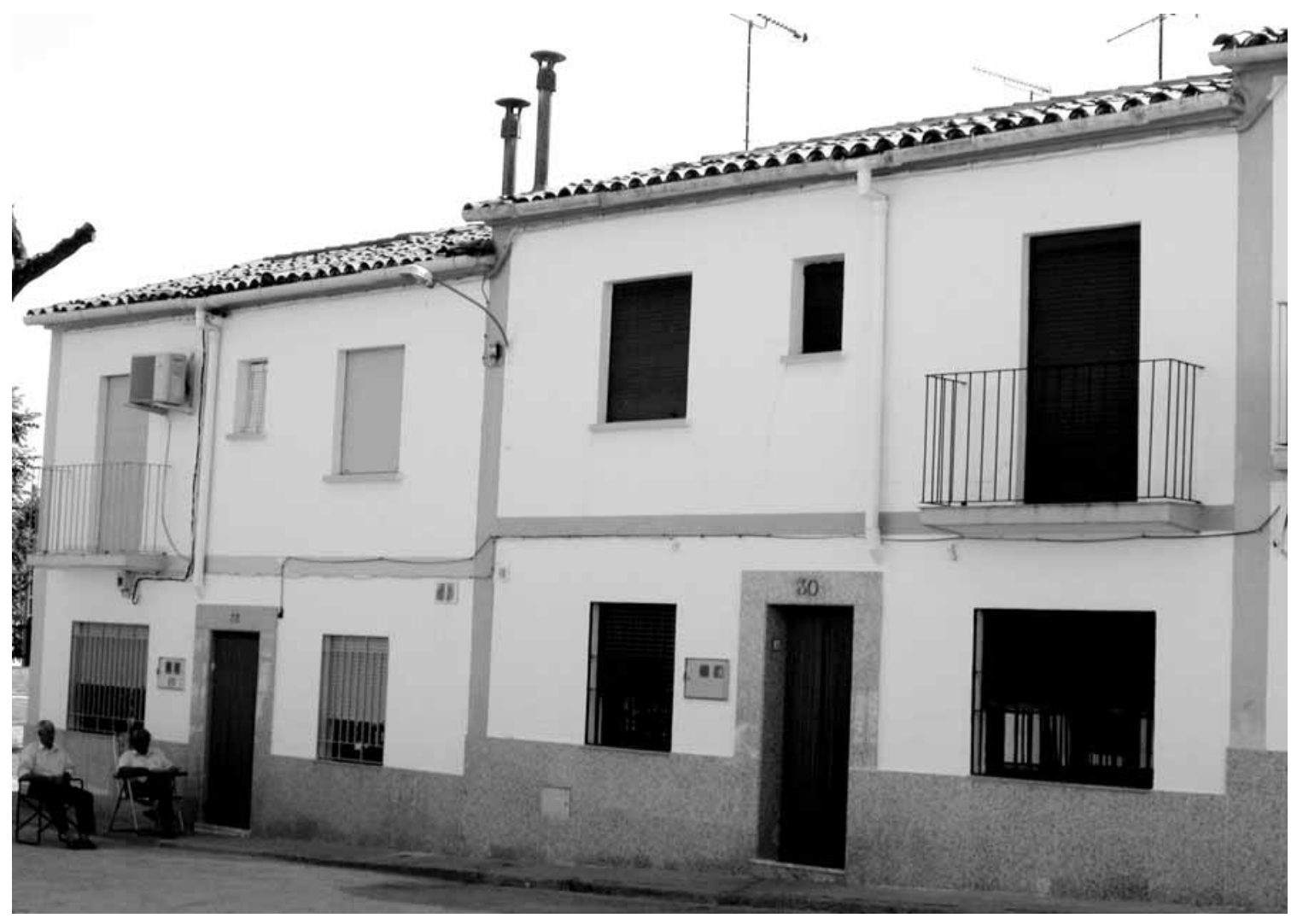

Fig. 9. Imagen actual de las casas de la calle Obispo Manzano 30 y 32, sede del IEAA durante su primera etapa en Jaraíz de la Vera. Mayo de 2006. Fototeca IHH. Colección Documental. Foto: García Vuelta.

Institucionalmente se produce además en esta etapa un hecho de gran importancia para la proyección del IEAA, su vinculación al CSIC a través de su patronato «Menéndez Pelayo», que fue aceptada a finales de diciembre de 1964 y hecha efectiva en 1965 (IEAA, 1973: 120; Colaborador, 1975: 10). A partir de este momento, y aunque continuó siendo «un centro autónomo», el IEAA experimentó un progresivo aumento de su actividad institucional y sus fondos (especialmente de su biblioteca); gracias a su vinculación al CSIC el centro logró también la obtención de certificados como editorial (Ver Gladius IV), y su afiliación a la UNESCO ${ }^{32}$.

En buena medida debido al optimismo ante la nueva y prometedora situación del instituto, los Hoffmeyer comenzaron ya desde principios de 1965 las gestiones para conseguir una ubicación más adecuada a sus fines ${ }^{33}$. Esta vez el matrimonio contaba con un importante apoyo para esta búsqueda, que le fue ofrecido por la Dirección Gral. de Bellas Artes ${ }^{34}$.

Nuevamente se opta como destino por la ciudad de Granada -al parecer tras una recomendación del embajador de España en Copenhague (Bruhn, 1985)-, emplazamiento que

32 Como se manifiesta en algunos documentos del centro (Bruhn, 1985). Según la correspondencia conservada en el Archivo del IEAA, la vinculación del IEAA con el CSIC fue aceptada el día 22 de diciembre de 1964. Una referencia sobre dicha vinculación fue publicada en el diario ABC, el 24 de diciembre de 1964 (Archivo IEAA. Sección Prensa, n. ${ }^{\circ}$ 364).

33 Archivo IEAA. Sección Asuntos especiales. Carpeta 13.

34 Archivo IEAA. Sección Asuntos especiales. Carpeta 13. Carta de Gratiniano Nieto, Director Gral. de Bellas Artes a Ada Bruhn ofreciendo ayuda para la búsqueda de la instalación del IEAA. 
además de satisfacer las inquietudes intelectuales del matrimonio -especialmente el interés de E. F. Hoffmeyer por el mundo hispano musulmán-, solucionaba los graves problemas de comunicaciones que el instituto venía padeciendo en Jaraíz de la Vera. La estancia del IEAA en Granada proporcionaba además al centro un mejor contacto con museos, bibliotecas y organismos oficiales.

A pesar de la ayuda institucional, las gestiones para el traslado no finalizaron hasta los primeros meses de 1966. Los importantes avances producidos por esas fechas hicieron que los Hoffmeyer se decidieran a abandonar Jaraíz de la Vera con destino a una residencia provisional en las inmediaciones de Granada, produciéndose su traslado en torno al 7 de marzo de $1966^{35}$. Sin embargo, la cuestión aún distaba de encontrarse totalmente resuelta.

\subsection{Estancia en Granada (Huétor Vega)}

La etapa granadina del IEAA, que se prolonga a lo largo de aproximadamente 4 años, ofrece una gran importancia para el análisis de la historia del centro, ya que marca un punto de inflexión entre sus primeras actividades «de establecimiento» en España y su situación posterior durante los años 70-90, que en buena medida son una consecuencia directa de los avatares sufridos durante esta fase.

A grandes rasgos, puede apuntarse que la estancia en Granada del IEAA estuvo marcada por tres factores estrechamente relacionados. En primer lugar, el creciente trabajo a desarrollar en el centro. En segundo lugar, un progresivo empeoramiento del estado de salud del matrimonio, provocado principalmente por la humedad del clima granadino, que ocasionará frecuentes interrupciones de su actividad. Por último, los problemas y demoras surgidos para culminar la esperada reubicación del IEAA, que poco a poco fueron minando las expectativas de los Hoffmeyer y motivarán finalmente su retorno a Jaraíz de la Vera.

Contando con el apoyo de la Dirección General de Bellas Artes, el matrimonio había viajado a Granada en junio de 1965, con el fin de inspeccionar posibles ubicaciones para su centro en espacios singulares de esta ciudad. Durante este viaje, se consideraron emplazamientos como la «Casa de los Cirones», el palacio de Daralahorra; la «Casa de los Porras» o la Casa árabe o morisca de Zafra, en el Albaicín, que fue finalmente la elegida ${ }^{36}$.

A la espera de poder culminar la operación, el matrimonio emprendió las gestiones para su traslado desde Jaraíz de la Vera ${ }^{37}$, adquiriendo previamente la finca Santa Elena, en la localidad de Huétor Vega -en las proximidades de Granada- como residencia temporal (Figs. 10 y 11$)^{38}$. La finca será sin embargo la sede del IEAA desde marzo de 1966 y durante toda la etapa granadina del centro.

35 La noticia del traslado se indicó en una carta a P. Longás el día 1/3/1966. Archivo IEAA. Sección Correspondencia. Carpeta «L».

${ }^{36}$ E. F. Hoffmeyer describe la casa de Zafra en su correspondencia con P. Longás: «Es parte del grupo de construcciones que constituye el convento de Santa Catalina de Zafra. Es una casa árabe completa, con patio que tiene salas y galerías de arcos pintados en los testeros con columnas y capiteles cúbicos interesantes, del tipo de los del patio de Mexuar en La Alhambra. Esta casa perteneció al secretario de los reyes católicos, Hernando de Zafra» Archivo IEAA. Sección Correspondencia. Carpeta «L». Carta a P. Longás, 16/11/1967. Las gestiones relativas a Zafra se recogen también en la sección Asuntos Especiales del Archivo del IEAA, Carpeta 13.

37 Para ello, vendió su residencia en Jaraíz e inició a largas y problemáticas gestiones para vender su finca de Benamejí, Córdoba (que no se ultimarán probablemente hasta finales de 1967).

38 «habitamos una villa en un suburbio como a dos kilómetros del centro de la capital. Disponemos sobre [sic] más metros cuadrados que en las dos casas de Jaraíz y todas las habitaciones están en la planta baja, excepto nuestro dormitorio, que está arriba. Hay jardín y huerto de unos 1200 metros. La casa tiene muros de casi un metro; en el terreno hay árboles que pacifican los ruidos de fuera. Es decir, que hay paz y tranquilidad para el trabajo. Quedamos muy contentos con el cambio de vivienda». Archivo IEAA. Correspondencia. Carpeta «A». Carta de E. F. Hoffmeyer a F. Jiménez, de Cuacos de Yuste, 29/4/1966. 
En los primeros meses de 1966 la situación del instituto era muy prometedora. Habiendo aceptado el Estado la opción de la casa de Zafra, se había dado inicio a las gestiones oficiales para la adecuada restauración del edificio, que actuaría como sede institucional del IEAA y como lugar de residencia del matrimonio. Los Hoffmeyer, por su parte, habían ofrecido al Estado hacer una fundación y donar a España su instituto ${ }^{39}$.

Con estos planteamientos, el matrimonio reanudó su trabajo desde Huétor Vega a la espera de la finalización de las obras de acondicionamiento de la casa de Zafra. Tras su instalación en la finca Santa Elena, una de las principales tareas desarrolladas, junto a la continuación de los estudios científicos de Ada Bruhn (p. ej. Bruhn, 1966), se centró en reorganizar y catalogar los fondos bibliográficos y el archivo fotográfico del centro. Como se ha señalado anteriormente, ambas tareas fueron emprendidas por E. F. Hoffmeyer (Colaborador, 1975: 10), que adquirió en Madrid parte de los muebles empleados para su organización y supervisó personalmente la
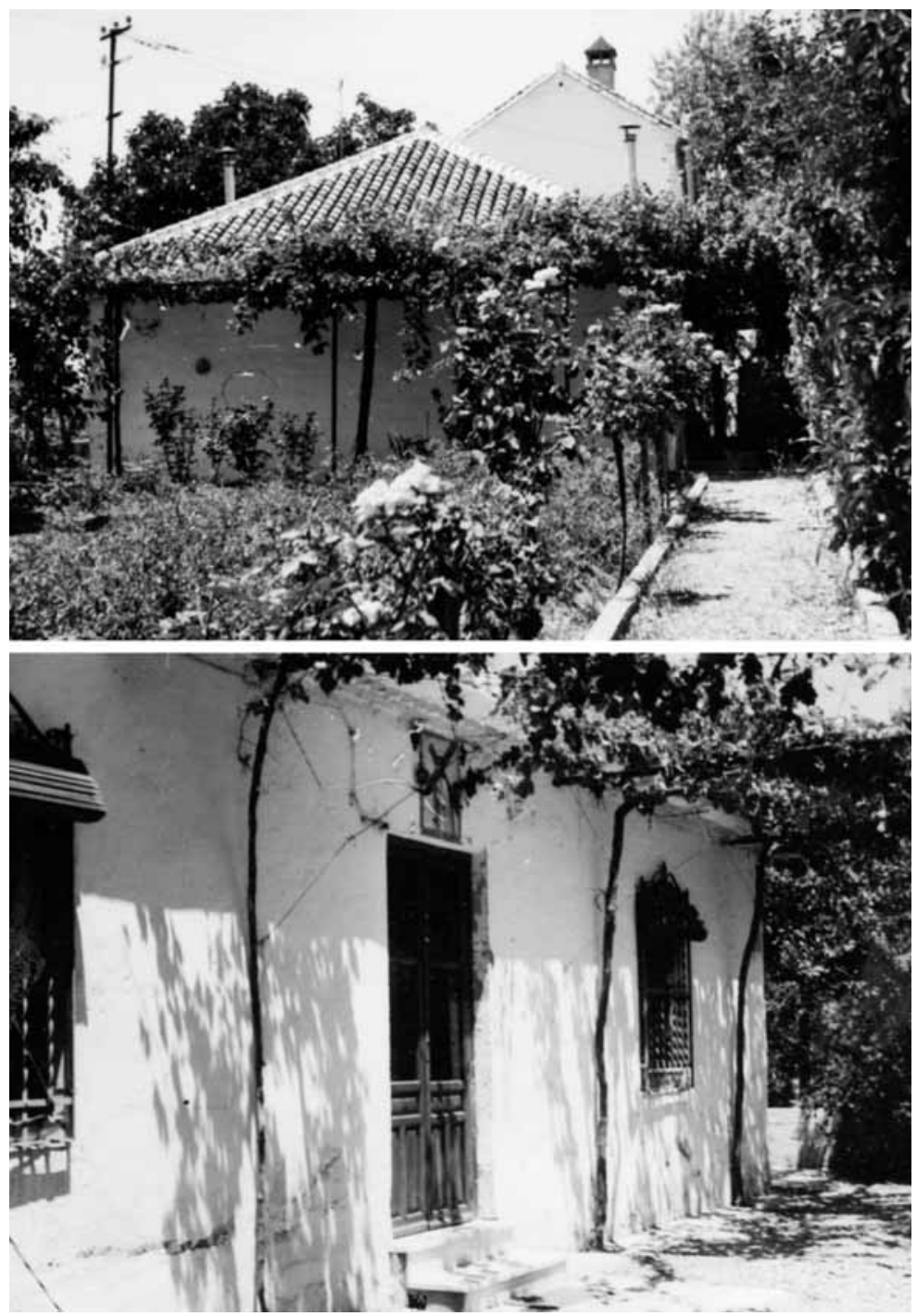

Fig. 10. La finca «Santa Elena», sede del IEAA en Huétor Vega (Granada), en 1966. Detalle parcial de la finca (Superior) y la entrada de la casa en la que se ubicó el centro (Inferior). Fototeca IHH. Colección Catalogada. Sección Generalidades. Reg. 1913.

construcción de las instalaciones ${ }^{40}$. Tampoco se descuidó el trabajo en Gladius; poco antes de su traslado desde Jaraíz, en febrero, los Hoffmeyer habían cancelado su acuerdo de distribu-

$39 «$ «l Estado Español tiene mucho interés en conservar nuestro instituto para España. Con este motivo Ada y yo hemos ofrecido hacer fundación del Instituto, y el Estado está restaurando la casa para instalar allí el instituto y una vivienda para nosotros. El Sr. Delegado del Ministerio de Información nos ha dicho que el Estado también intenta colocar una colección de armas antiguas en la misma casa (en la planta baja). El instituto y nuestra vivienda están en la planta alta». Archivo IEAA. Correspondencia. Carpeta «L». Carta a P. Longás, 16/11/1967. Ver también Archivo IEAA. Sección Asuntos especiales. Carpeta 13.

40 «La mudanza salió bien, pero nos costó mucho dinero. Todavía no hemos terminado la instalación del Instituto. En esta semana viene un carpintero todos los días para hacer nuevas estanterías y otras cosas. Cuando haya terminado su trabajo podemos colocar los libros, documentos y grabados y fotos de armas y objetos arqueológicos como queremos». Archivo IEAA. Correspondencia. Carpeta «A». Carta de E. F. Hoffmeyer a F. Jiménez, 29/4/1966. 


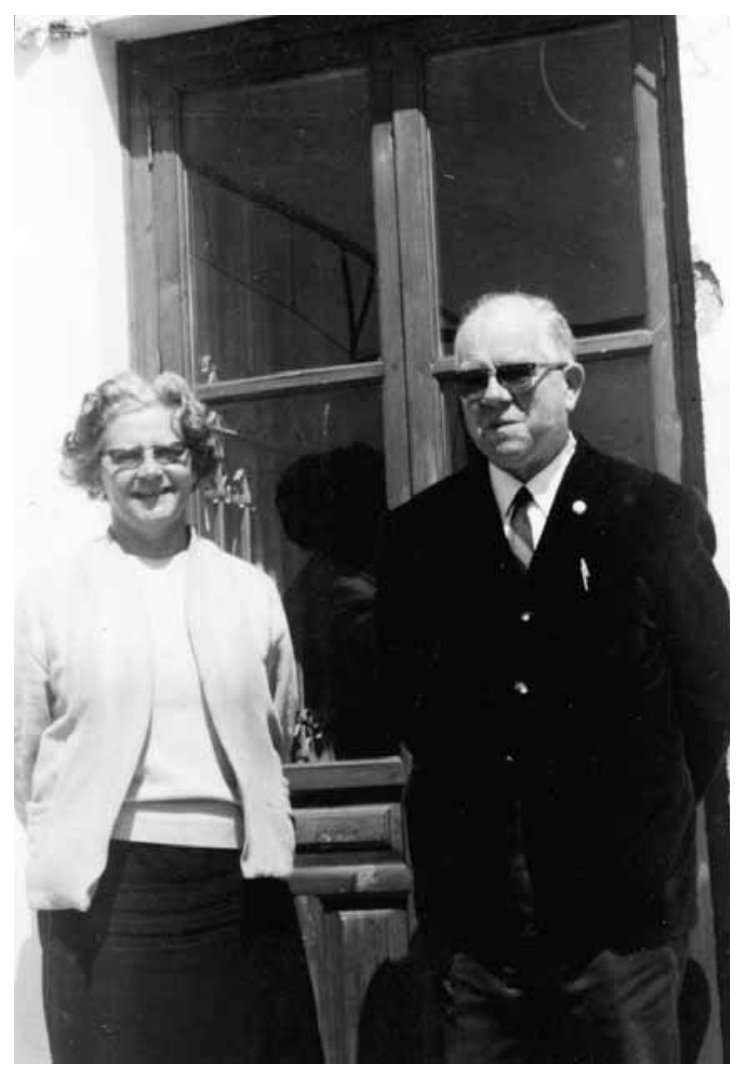

Fig. 11. El matrimonio Hoffmeyer en la Finca «Santa Elena», en 1967. Fototeca IHH. Colección personal Hoffmeyer.

ción con Insula ${ }^{41}$, retomando toda la gestión editorial. El tomo IV de la revista, que había sido ya preparado en Jaraíz de la Vera, será publicado desde Granada. A partir de este número, E. F. Hoffmeyer figurará como director de la revista, y Ada Bruhn como directora del IEAA. Durante la etapa granadina aparecerán también los volúmenes V (1966) y VI (1967) de Gladius.

\section{El fin de las gestiones de Zafra}

El 23 de octubre de 1967 se ultimó un acuerdo oficial de cesión y uso del edificio de Zafra $^{42}$ cuyas obras, salvo algunas reformas, parecían haber finalizado en noviembre de $1967^{43}$. El día 11 de este mes, los Hoffmeyer expresaban su intención de vender la finca de Huétor Vera y confirmaban a la Dir. Gral. de Bellas Artes su voluntad de donar el IEAA al Estado $^{44}$

Sin embargo, y aunque el matrimonio llegó a recibir las llaves de la casa de Zafra, la ya larga espera se complicó debido a nuevos e inesperados problemas de carácter presupuestario, surgiendo además graves desacuerdos y fricciones con los responsables de su ejecución, que dieron como resultado un estancamiento de las obras ${ }^{45}$.

Debido a esto, los Hoffmeyer -cuyo estado de salud se había visto notablemente afectado durante su estancia en Huétor- se mostraban ya muy pesimistas con el adecuado fin de las gestiones, decidiéndose desde septiembre de 1968 a entablar una nueva serie de contactos para facilitar un nuevo traslado del centro. Como destino vuelve a considerarse Extremadura, en esta ocasión fundamentalmente por sus mejores condiciones climáticas ${ }^{46}$.

Los documentos conservados indican la intención del matrimonio de trasladar el instituto a la provincia de Cáceres, llegando a realizar varios viajes en este sentido a finales de $1968^{47}$ y principios de 1969. Por estos momentos, se barajaron posibles emplazamientos en ciudades

41 Archivo IEAA. Sección Asuntos especiales. Carpeta 10.

42 Archivo IEAA. Sección Asuntos especiales. Carpeta 13.

43 «Ya han terminado la restauración de la casa de Zafra. Pero todavía faltan algunas cosas que arreglar. Hemos firmado un contrato con Bellas Artes [23/10/1967] según el cual nos conceden residencia gratuita por el resto de nuestra vida en dicha casa. Pero como hace mal tiempo no queremos comenzar una mudanza con tantas cosas por ahora». Archivo IEAA. Correspondencia. Carpeta «L». Carta a P. Longás, 16/11/1967.

44 Archivo IEAA. Sección Asuntos especiales. Carpeta 4.

45 Archivo IEAA. Sección Asuntos especiales. Carpetas 4 y 13.

46 «Debido al clima de Granada mi esposa y yo hemos estado enfermos, lo que ha retrasado nuestro trabajo mucho. Con tal motivo tenemos mucho interés en trasladarnos a un clima más seco tan pronto como sea posible». Carta de E. F. Hoffmeyer al Comisario Gral. del Patrimonio Artístico Nacional, 14/2/1969. Archivo IEAA. Sección Asuntos especiales. Carpeta 4.

47 Uno de ellos en septiembre de 1968; al menos un segundo viaje a Extremadura (Cáceres y Trujillo) tuvo lugar entre diciembre de 1968 y enero de 1969. 
como Cáceres, Trujillo o Plasencia, e incluso la posibilidad de su instalación en el castillo de Manzanares el Real, en la provincia de Madrid ${ }^{48}$.

Finalmente, tras los últimos intentos de E. F. Hoffmeyer de solucionar la situación en Granada, éste informó al Delegado Provincial de Bellas Artes el 11 de septiembre de 1969 de su decisión de dar por cancelado el acuerdo de cesión, así como del inicio de sus gestiones para la adquisición «de otro local en otra provincia». Un día después, los Hoffmeyer dieron igualmente cuenta de la situación a la Dir. Gral. de Bellas Artes, a la que informaron de sus gestiones para el traslado del IEAA a Extremadura, de las opciones geográficas valoradas hasta el momento, y de su voluntad de adquirir en breve un edificio adecuado.

De esta manera se puso fin oficialmente a la etapa granadina del instituto. Los Hoffmeyer abandonaron su finca de Huétor Vega en marzo de $1970^{49}$, trasladándose nuevamente ante el fracaso de las gestiones realizadas a Jaraíz de la Vera, donde el IEAA quedará ubicado definitivamente.

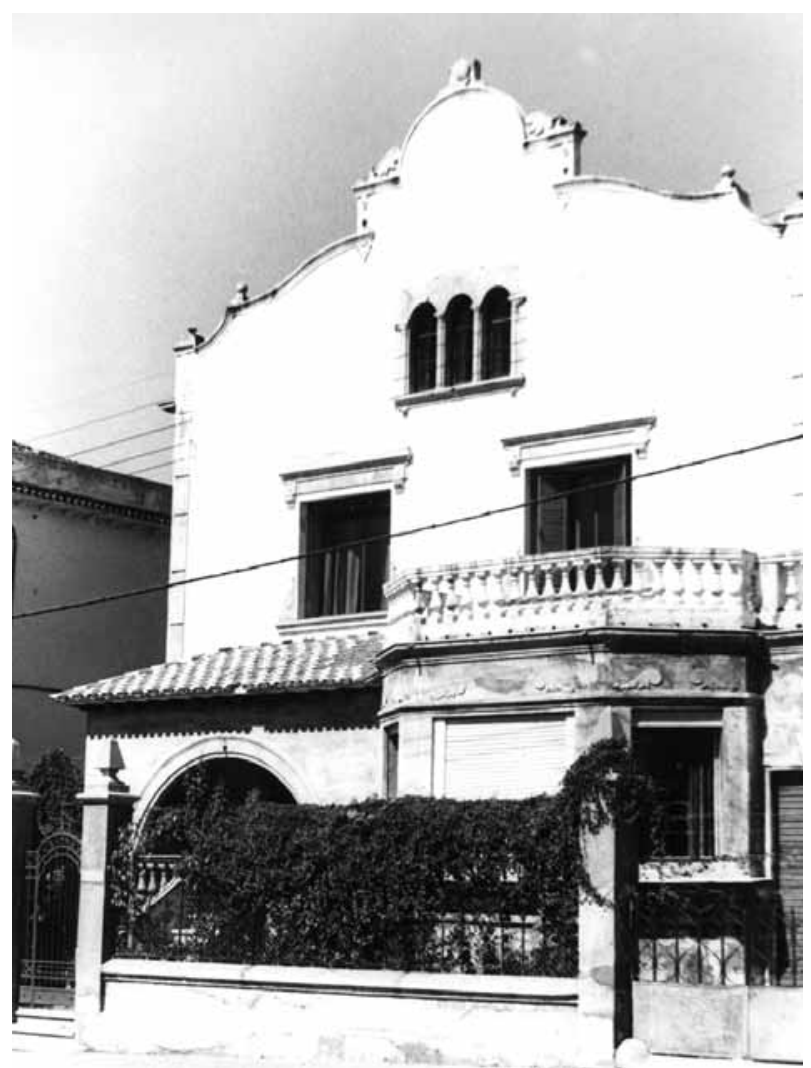

Fig. 12. Detalle del exterior de «Villa Guadalupe», en Jaraíz de la Vera. 1973. Fototeca IHH. Colección Catalogada. Sección Generalidades. Reg. 1774. Foto Goya.

\subsection{Segunda estancia en Jaraíz de la Vera}

Según los datos conservados, el traslado a Jaraíz de la Vera se produjo en marzo de 1970, sin que contemos hasta el momento con referencias suficientes para la adecuada documentación de los meses inmediatamente anteriores y posteriores a su llegada, que parecen dedicarse a un período de descanso y a la reforma de la nueva sede del centro ${ }^{50}$. El IEAA se asentó definitivamente en «Villa Guadalupe», una espaciosa casa chalet que teóricamente respondía a las necesidades de trabajo de la institución (Figs. 12 y 13$)^{51}$.

A diferencia de su primera estancia en la localidad cacereña, los inicios de esta nueva etapa estuvieron caracterizados por un notable incremento del volumen de trabajo en el

\footnotetext{
48 Archivo IEAA. Sección Asuntos Especiales. Carpeta 4.

49 Según se anotó en las fotografías de la finca conservadas en la Fototeca del IHH (Colección Catalogada. Sección Generalidades, Reg. 1913).

50 Según la correspondencia del matrimonio en noviembre y diciembre de 1969, parece que ya se habría adquirido por estos momentos una casa en Jaraíz de la Vera (Archivo IEAA. Carpeta «Robles-Santillana»), como también se indicó en la correspondencia ya citada con la Dir. Gral. de Bellas Artes. La fecha oficial de compra de la nueva residencia del IEAA en esta localidad data sin embargo de diciembre de 1971 (ver nota siguiente).

51 Ubicada en la actual Avda. de la Constitución 114 (antigua Avda. del Generalísimo 104). El inmueble fue adquirido a Luis García Sánchez el 21 de diciembre de 1971, según consta en el legado de cesión del IEAA al CSIC. Encontramos también una descripción de la nueva sede en la correspondencia mantenida con Pedro Longás en 1970. Archivo IEAA. Sección Correspondencia. Carpeta «A».
} 

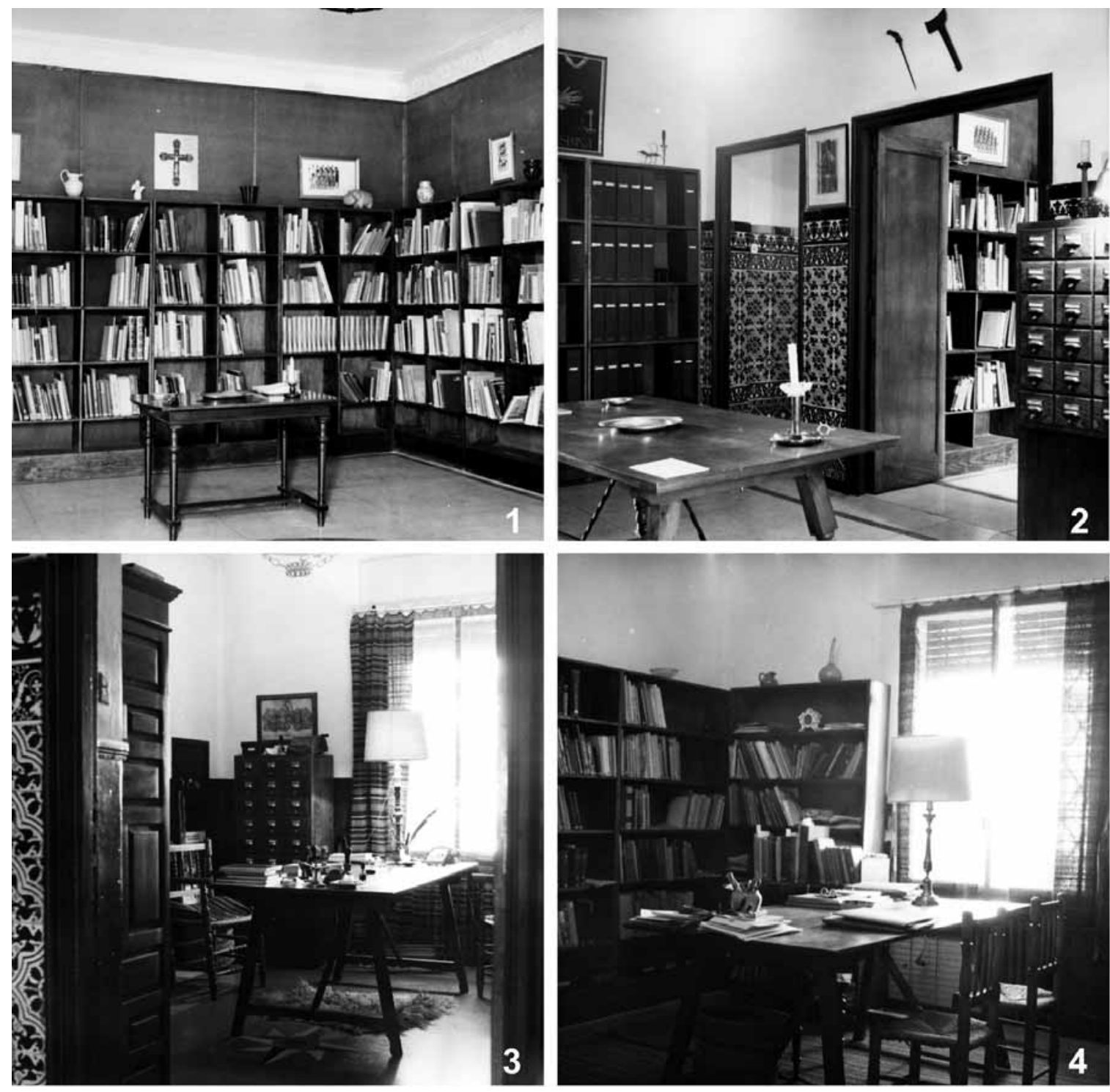

Fig. 13. Algunas de las instalaciones del IEAA en 1974: 1. Detalle de la biblioteca; 2. Detalle de los armarios de fototeca y los archivadores para biblioteca; 3 y 4 . Despachos de trabajo de los Hoffmeyer. Fototeca IHH. Colección Catalogada. Sección Generalidades. Regs. 2165, 2166, 2168 y 2169 . Fotos: Goya.

IEAA. De forma obligada, una de las primeras tareas desarrolladas fue la reinstalación de su extensa biblioteca, así como de su fototeca y archivos, que quedaron ubicadas en la planta baja del edificio (Fig. 13). Se continuó igualmente el trabajo de edición de Gladius, que debido a las circunstancias anteriores se había visto retrasado. En esta época, se publicaron los tomos VII (1968), VIII (1969) y IX (1970) de la revista, y vieron también la luz algunos importantes trabajos de Ada Bruhn (Bruhn, 1971). El instituto continuó igualmente su labor científica e institucional, como pone de manifiesto el nombramiento del matrimonio como Correspondiente del Museo del Ejército a mediados de octubre de 1973 (Hoffmeyer 1974: 140-141). 
Sin embargo, estos primeros años en Jaraíz estuvieron también profundamente marcados por unas muy malas relaciones entre los Hoffmeyer y las autoridades locales. Estas dificultades, que se iniciaron según los documentos conservados de una forma casi inmediata al establecimiento del centro en «Villa Guadalupe», se vieron además acompañadas por numerosos problemas con los transportes y comunicaciones postales. Ambas circunstancias dieron lugar a frecuentes fricciones que afectaron muy negativamente a la convivencia del matrimonio en la localidad, entorpeciendo su labor en la institución, muy especialmente en lo relativo a la distribución y edición de Gladius $^{52}$. Esto motivó nuevos retrasos en la revista y la decisión de trasladar su dirección postal y la estafeta del instituto a la cercana localidad de Jarandilla de la Vera, figurando con esta referencia los volúmenes X (1972) y XI (1973), publicados respectivamente en 1973 y 1974.

Nuevamente desalentados por la situación, los Hoffmeyer optan una vez más por trasladar el instituto, decisión que ponen de manifiesto tanto en su correspondencia personal como en las publicaciones oficiales del centro al menos desde 1973 (IEAA, 1973: 120 y 122; Hoffmeyer, 1974: 139-140) ${ }^{53}$. Sin embargo, este traslado no llegará a producirse, quedando los planes interrumpidos por la muerte de E. F. Hoffmeyer en abril de 1975.

El fallecimiento del director de Gladius y organizador de la biblioteca, fototeca y archivos del IEAA, hizo recaer sobre los hombros de Ada Bruhn todo el peso del trabajo en la institución ${ }^{54}$. A pesar de ello, la investigadora siguió desarrollando su actividad científica, dirigiendo y financiando hasta sus últimos años la labor del instituto y de su revista. El volumen XII de Gladius (1974), dedicado a E. F. Hoffmeyer -y en el que como se ha comentado éste se encontraba trabajando en sus últimos momentos- fue publicado en 1975. En este período, y hasta finales de los años 70, verán la luz dos números más de la revista; los volúmenes XIII (1977) y XIV (1978), así como varias monografías (Nicolle, 1976; Martínez del Peral, 1980 o Bruhn, 1982). En homenaje a su marido, Ada Bruhn rebautizó las instalaciones del IEAA con el nombre de «Casa Fernando Hoffmeyer» (Ver Gladius XIII).

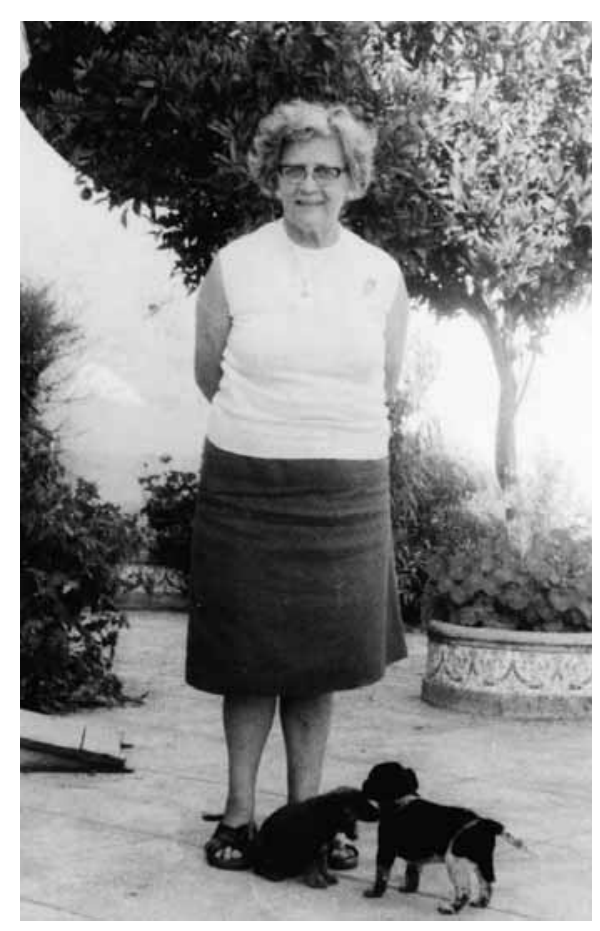

Fig. 14. Ada Bruhn en «Villa Guadalupe». Año 1972. Fototeca IHH. Colección Personal Hoffmeyer.

52 La documentación relativa a estos problemas quedó recogida en la sección de Asuntos Especiales del Archivo del IEAA.

53 «... we are sorry to tell that we during the last three years have been troubled with unexpected, very often absurd obstacles, irrelevant to the normal function of a scientific research institution, problems of LOCAL character which have caused much waste of time.. We hope that we shall succeed in finding better conditions for our work in the future.» (IEAA, 1973: 122). En la memoria publicada en 1974 (Gladius XI), E. F. Hoffmeyer manifestará que «..seguimos buscando un edificio apropiado, situado en un lugar que ofrezca buenas condiciones para trabajo intelectual y buenas comunicaciones, tanto postales como ferroviarias...» (Hoffmeyer, 1974: 141).

54 La documentada necrológica de E. F. Hoffmeyer publicada en 1975 en Gladius XII supone también una de las primeras publicaciones que dan cuenta de las vicisitudes experimentadas por el instituto desde su fundación (Colaborador, 1975: 11). Tras el fallecimiento de su marido, Ada Bruhn asumió todas las tareas relativas a la publicación de Gladius, incluyendo desde la corrección y revisión de los originales hasta el transporte de los ejemplares a Jarandilla de la Vera para su posterior distribución. Agradezco a Álvaro Soler sus informaciones sobre la incansable actividad de la investigadora durante estos años. 
Afortunadamente, y principalmente desde mediados de los años 80 la situación del instituto cambió, abriéndose un período caracterizado por una gran mejora de sus relaciones institucionales locales. Durante esta última fase de su actividad, y a pesar de haber recibido algunas propuestas para el traslado del IEAA, Ada Bruhn decidió mantener la institución en Jaraíz de la Vera ${ }^{55}$. En estos años, y a pesar de su avanzada edad, la investigadora se esforzó en mantener la edición de Gladius -cuyos volúmenes XV, XVI y XVII vieron la luz respectivamente en 1980, 1983 y 1986-, publicó algunos de sus trabajos más significativos (p.ej. Bruhn, 1982), y retomó la ardua tarea de continuar la clasificación y catalogación de las colecciones de imágenes del IEAA. Para este trabajo, Ada Bruhn contó esta vez con la colaboración intermitente de un ayudante financiado desde el Ayuntamiento de Jaraíz de la Vera $^{56}$.

La investigadora no descuidó en esta etapa su labor de atención especializada a coleccionistas y estudiosos. Entre los investigadores españoles que mantuvieron un especial contacto con Ada Bruhn de Hoffmeyer desde mediados y finales de los años 70 podemos destacar entre otros a Victoria Cirlot (UPF) ${ }^{57}$ y especialmente a Álvaro Soler del Campo, actual conservador de la Real Armería de Madrid y codirector de Gladius, con la unió una gran $\operatorname{amistad}^{58}$.

Tampoco fueron desatendidas durante este período las relaciones académicas e institucionales del instituto; un buen ejemplo lo constituyen las mantenidas a finales de los 80 con la Universidad de Extremadura, que dieron como fruto la publicación del simposio internacional «Las Armas en la Historia», organizado por el Dpto. de Historia Medieval de dicha universidad en 1987. Las actas de esta reunión, que verán la luz en 1988, constituyen la última de las publicaciones editadas desde el centro, encontrándose en preparación a la muerte de Ada Bruhn el volumen XVIII de Gladius y una monografía de la investigadora dedidada al armamento en los primeros tiempos de la conquista de América ${ }^{59}$, que lamentablemente no llegaron a publicarse.

Hasta sus últimos momentos, Ada Bruhn se preocupó especialmente de asegurar la adecuada continuidad del IEAA. En ese sentido, y desde la segunda mitad de los años 80, había iniciando diferentes contactos institucionales que no llegaron a prosperar ${ }^{60}$, aunque hasta sus últimos años siguió reiterando su deseo de que el centro permaneciese en España, y especialmente en Extremadura (Sánchez Ocaña, 1988: 11). En el mes de marzo de 1989, Ada Bruhn redactó testamento legando el Instituto y sus fondos al CSIC, cesión que se hizo efectiva tras su fallecimiento. De forma puntual, algunos materiales fueron también donados a otras personas e instituciones (Cabrera, 1995).

55 Ver por ejemplo Archivo IEAA. Sección Correspondencia. Carpeta «Varios 1979». Correspondencia con V. Cirlot en junio de 1979, sobre la posible ubicación del centro en Barcelona.

56 Agradecemos a D. J. C. Cepeda, ayudante de Ada Bruhn en este período su información sobre estas actividades. El centro también contó con ayuda de personal en los temas relativos a las comunicaciones postales del centro, lo que permitió una sustancial mejora en este sentido.

57 Durante el período de preparación de su memoria de licenciatura El armamento catalán de los siglos XI al XIII (UAB, 1977) y de su tesis doctoral. El armamento catalán de los siglos XI al XIV (UAB, 1980), junto a otros trabajos (Cirlot, 1978 y 1980 b). Agradecemos D. ${ }^{a}$ V. Cirlot sus amables informaciones sobre este período.

58 A lo largo del período de preparación de su memoria de licenciatura El armamento medieval en la Peninsula Ibérica, siglos X y XI (UCM, 1985), (Soler, 1987) y su tesis doctoral La evolución del armamento medieval en el reino castellano-leonés y Al-Andalus (siglos XII-XIV), (UCM, 1991), (Soler, 1991 y 1993), de la que Ada Bruhn fue miembro del tribunal en octubre de 1990. Agradecemos a D. Alvaro Soler del Campo sus informaciones en este sentido.

59 Agradecemos nuevamente a D. Alvaro Soler del Campo esta información.

60 Pueden destacarse, entre otros, los mantenidos con el Museo del Ejército. 


\subsection{Cierre y reformas en el IEAA. La creación del Instituto Histórico Hoffmeyer (1991-1997)}

Después del cierre temporal del centro, y una vez concluido el proceso legal de aceptación del legado de Ada Bruhn de Hoffmeyer por parte del CSIC en 1992, se abrió un período de toma de decisiones respecto al futuro del IEAA. Considerada finalmente la permanencia de todos sus fondos en su sede de Jaraíz de la Vera, se da comienzo en 1995 a las obras de restauración de sus instalaciones, que fueron financiadas por la Junta de Extremadura (Serradilla, 1997: 10).

A lo largo de este período, las colecciones bibliográficas y documentales, así como los muebles y otros materiales conservados en las dependencias del instituto fueron trasladados a diferentes ubicaciones. Tanto los fondos bibliográficos -en parte deteriorados por el surgimiento de humedades en «Villa Guadalupe» durante el período de inactividad del centro ${ }^{61}$ como los archivos documentales fueron almacenados temporalmente en la Casa de la Cultura de Jaraíz.

Finalizada la reforma de Villa Guadalupe, los materiales del IEAA fueron nuevamente transferidos a esta sede, donde han permanecido hasta la fecha. El centro volvió a abrir sus puertas a principios de julio de 1997 (Cruz, 1998: 44) ${ }^{62}$. Como resultado de las reformas realizadas puede destacarse la ampliación de sus espacios de biblioteca y hemeroteca, o la habilitación de nuevas dependencias administrativas y de trabajo. ${ }^{63}$

El 4 de febrero de 1998, se firmó el convenio del patronato del Instituto Histórico Hoffmeyer, iniciándose así una nueva singladura de la institución. El patronato del IHH está integrado por el CSIC, la Junta de Extremadura (a través de su Consejería de Cultura y Patrimonio); la Diputación Provincial de Cáceres, el Ayuntamiento de Jaraíz de la Vera, Patrimonio Nacional y la Caja de Extremadura (Cruz, 1998: 44). ${ }^{64}$

Como ya se ha señalado, en 1999 el CSIC retomó igualmente la publicación de Gladius, que reapareció con una periodicidad anual, un formato de mayor calidad y un significativo incremento en sus contenidos respecto a su etapa anterior ${ }^{65}$. Desde el inicio de esta nueva etapa, la dirección de la revista fue asumida por los reconocidos especialistas en los campos de la Arqueología y la Historia de las Armas Antiguas Fernando Quesada Sanz (Universidad Autónoma de Madrid) y Álvaro Soler del Campo (Real Armería de Madrid), cuya labor al frente de la publicación ha continuado hasta la actualidad.

Hoy día, Gladius continúa siendo la más importante y casi la única revista española dedicada a estos temas ${ }^{66}$ y sigue constituyendo el principal órgano de expresión del IHH, cumpliéndose así el objetivo de proporcionar una adecuada continuidad y renovación a la tradición científica de la institución fundada por el matrimonio Hoffmeyer. Sus aportaciones se

61 Que hicieron necesaria la aplicación de posteriores tratamientos de conservación, a pesar de los cuales el fondo se vio mermado. Agradecemos a José Vicente Serradilla Muñoz (IHH), contratado como responsable del centro durante estos años, sus interesantes informaciones sobre ese período.

62 La noticia de la conclusión de las reformas de Villa Guadalupe apareció en la prensa extremeña en el mes de mayo de 1997, recogiéndose igualmente referencias a las actividades para la recuperación de los fondos bibliográficos del centro (Serradilla, 1997).

${ }^{63}$ Contando en la actualidad el centro con un apartamento y habitaciones para investigadores; almacenes; laboratorio de arqueología y salas de actos y reuniones.

${ }^{64}$ La primera directora del nuevo Instituto Histórico Hoffmeyer fue Pilar López García (IH, CSIC), a la que sucedió en 2002 J. Ramón Urquijo Goitia (IH, CSIC). En julio de 2006, la dirección del centro fue asumida por Leoncio López-Ocón Cabrera (IH, CSIC).

65 http://www.ih.csic.es/publicaciones/gladius.htm

66 Como consta en la línea editorial de la revista, sus principales temas de interés se centran actualmente en el estudio de las armas antiguas; la guerra en Europa, el mundo colonial americano y el Islam; el arte militar; la polemología y la vida cultural desde la Prehistoria hasta finales del S. XVIII. Sus contenidos abarcan toda la geografía del globo. 


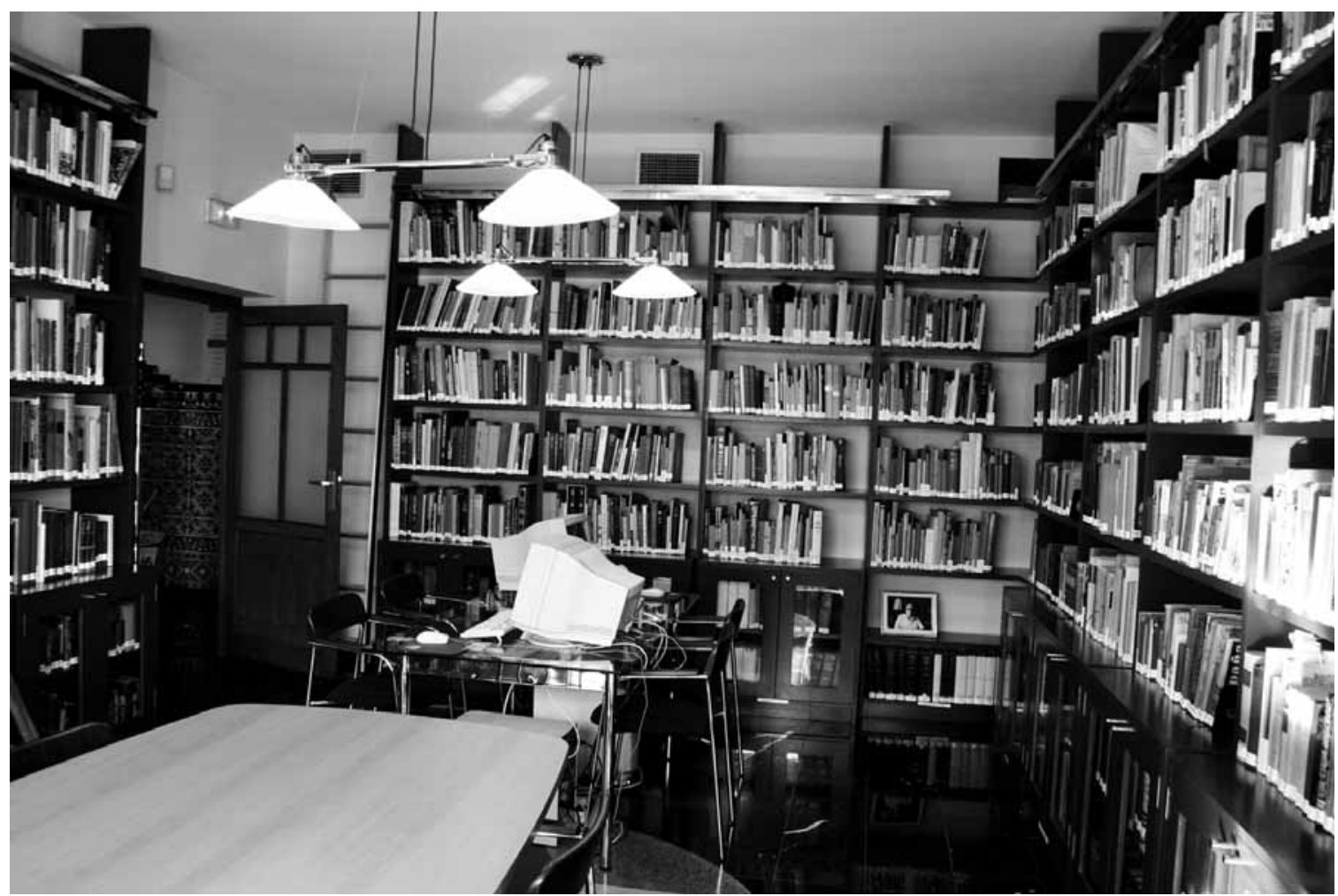

Fig. 15. La biblioteca del Instituto Histórico Hoffmeyer en la actualidad. Fototeca IHH. Colección Documental. Foto García Vuelta.

han visto además enriquecidas a lo largo de esta etapa con la aparición en 2002 de Anejos de Gladius, serie que continua la colección de monografías editadas desde el IEAA (Bruhn, 1972 y 1982; Nicolle, 1976, o Martínez del Peral, 1980) y que ha hecho posible la publicación de varios títulos de especial interés para la investigación (García-Bellido, 2006 y 2004; García Jiménez, 2006; Sáez, 2005; Gabaldón, 2004; Morillo, 2002).

\section{Algunos COMENTARIOS SOBRE LOS FONDOS DEL ANTIGUo IEAA}

Una vez terminado este rápido repaso a la historia y los avatares de la institución, es necesario apuntar a modo de conclusión algunas breves referencias sobre los principales fondos aportados por el antiguo IEAA, que junto a su Archivo Institucional y Personal, constituyen una parte fundamental del legado de los Hoffmeyer ${ }^{67}$.

67 Como sucede con la propia figura de la institución, el archivo del IEAA es difícilmente desvinculable del fondo documental personal de matrimonio Hoffmeyer, encontrándose ambos unidos en buena parte de su estructura y contenidos. Al igual que sucedió con la mayor parte de los fondos del centro, su correcta organización quedó incompleta debido al excesivo volumen de trabajo acumulado por Ada Bruhn tras el fallecimiento de su marido, responsable inicial de su sistematización. Hay que volver a señalar además que parte de su estructura original se perdió debido a los movimientos realizados en el periodo de reformas del centro. En la actualidad, la identificación, organización y catalogación de estos documentos constituye una de las tareas que se vienen desarrollando en el IHH. 


\section{La Biblioteca}

Tuvo su origen en los fondos personales del matrimonio Hoffmeyer y creció a lo largo de las distintas etapas de actividad del centro, a través de adquisiciones, donaciones, o por el intercambio institucional de Gladius. Como se ha visto en apartados anteriores, el responsable de su organización y catalogación por el sistema CDU fue E. F. Hoffmeyer, que realizó esta tarea a lo largo de las sucesivas etapas del centro, fundamentalmente a partir de su estancia granadina. Con el tiempo, la biblioteca del IEAA llegó a convertirse en una de las más importantes en Europa en su género, y en la más importante en España, constituyendo un auténtico punto de referencia para los estudiosos en esta materia (Soler, 1991 b: 8).

En 1988, Ada Bruhn estimó los fondos bibliográficos del IEAA en 10000 títulos aproximadamente, incluyendo todas sus colecciones de monografías, revistas y folletos dedicados fundamentalmente a armas antiguas y arqueología (Sánchez Ocaña, 1988: 11), junto a obras de referencia especializadas, catálogos, etc. Desde el punto de vista temático, las colecciones del IEAA abarcan un amplio abanico no solamente dentro del campo de la historia de las Armas Antiguas, sino también de la arqueología, heráldica, etc. Algunos de los contenidos de la biblioteca fueron descritos por la propia Ada Bruhn durante la última etapa de actividad del instituto (Bruhn, 1985):

«Armas y armamento en general, y [obras] especificas sobre: espadas, sables, rapieras, dagas, navajas, toda clase de armas de asta (lanzas, javelinas, espontones, alabardas, etc), armaduras, cascos, escudos, armas de fuego antiguas y hasta casi nuestro tiempo, para guerra, lujo, caza, deportes, armamento para torneos, para caballos, ballestas, arcos, artillería antigua (poliorcética antigua y medieval) sin pólvora, artillería con pólvora, cañones desde los primeros [tiempos] hasta el siglo pasado, castillos, armamento hispanoÁrabe, de India, Japón, etc., esgrima y otra clase de deporte[s]. Hay libros sobre arte militar y guerra antigua, Cruzadas, guerra medieval, armamento de la época de los Reyes Católicos, Carlos V, Felipe II, etc. Además hay literatura sobre la Conquista de HispanoAmérica y la cultura del Nuevo Mundo.. Heráldica...»

A pesar de la gran labor realizada por el matrimonio en lo referente a la ampliación y gestión de estos fondos bibliográficos, parte de los mismos quedaron sin catalogar a la muerte de la investigadora, sufriendo como se ha comentado un significativo deterioro durante el período de cierre de la institución. En ese sentido, una de las primeras líneas de trabajo desarrolladas tras la creación del Instituto Histórico Hoffmeyer se centró en la reorganización e informatización de la biblioteca y hemeroteca del instituto ${ }^{68}$. En la actualidad, y prácticamente concluida esta tarea, la biblioteca del IEAA ha quedado integrada en la Red de Bibliotecas del CSIC $^{69}$, y su fondo sigue incrementándose gracias a los intercambios nacionales e internacionales de Gladius.

\section{La Fototeca}

Las colecciones de imágenes en diferentes formatos que componen la fototeca especializada del IEAA proceden fundamentalmente de las publicaciones editadas por el centro y de las investigaciones llevadas a cabo por sus fundadores. Está formada por más de 10000 archivos

68 Labor llevada a cabo principalmente por el anterior responsable de la biblioteca del IHH, Juan Pedro López Monjón (CH, CSIC), a quien agradecemos sus orientaciones en ese sentido.

69 http://www.csic.es/cbic/bibliotecas/HM.htm. La consulta de los fondos bibliográficos del IHH puede realizarse a través de los catálogos informatizados del CSIC (http://aleph.csic.es) o mediante la visita al centro. Parte de las colecciones de folletos se encuentran aún en fase de catalogación. 


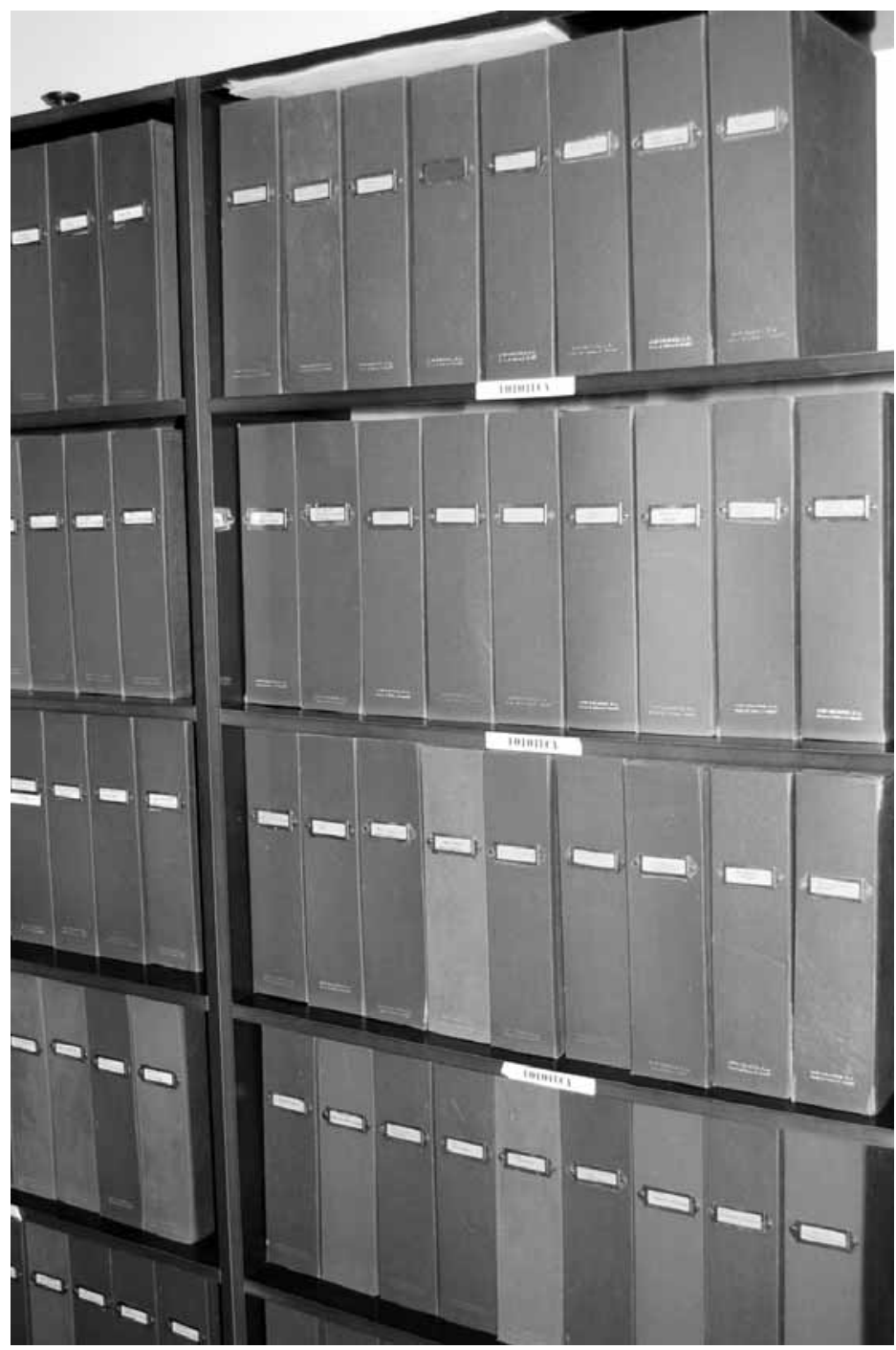

Fig. 16. Detalle del archivo de imágenes de la fototeca del antiguo IEAA. Fototeca del IHH. Colección documental. Foto: García Vuelta.

gráficos, de los cuales aproximadamente 8000 -sin contar documentos secundarios- se centran en el estudio de las armas antiguas.

Esta fototeca constituye sin duda una de las más valiosas herramientas para la documentación de la historia y la evolución del centro, así como para el estudio biográfico de sus fundadores. Su organización fue iniciada por E.F. Hoffmeyer de una forma posterior a los primeros trabajos de catalogación de la biblioteca, probablemente a finales de $1967^{70}$. Para ello, recurrió igualmente al sistema CDU y a la elaboración de fichas de clasificación donde quedaron fijadas las imágenes, acompañadas de información iconográfica, temática, cronológica y de referencia. Todas las fichas fueron inventariadas y almacenadas en cajas clasificadoras ordenadas temáticamente y adquiridas al efecto en Madrid (Fig. 16). Para la gestión de este archivo, se desarrollaron igualmente ficheros de información sobre las imágenes, que incorporan aproximadamente 3700 fichas, convenientemente organizadas en muebles clasificadores (Fig. 17, superior).

Como se ha señalado, tras el fallecimiento de E. F. Hoffmeyer el trabajo con la fototeca del centró recayó sobre Ada Bruhn, llegando a alcanzarse a finales de los años 80 la cifra de unas 3000 imágenes catalogadas (Sánchez Ocaña, 1988), aunque por desgracia la investigadora no pudo concluir el estudio completo de estas colecciones. De esta manera, a los archivos completamente catalogados se suman además otros 2000 documentos ordenados temáticamente y un fondo formado por aproximadamente 1100 documentos sin catalogar. A lo anterior se añade una singular colección de clichés metálicos, derivados del proceso de edición de las imágenes incorporadas tanto en Gladius como en otras publicaciones del centro (Fig. 17). Esta colección, que fue convenientemente organizada por los Hoffmeyer, cuenta en la actualidad con unos 1500 ejemplares, acompañados de sus correspondientes resultados de impresión en papel.

70 «Estoy para terminar el inventario de la biblioteca. Ha tardado más tiempo de lo pensado. Dentro de poco comenzaré la clasificación de las fotos y grabados. Hay muchísimos, no sabemos cuántos».Archivo IEAA. Correspondencia. Carpeta «L». Carta de E. F. Hoffmeyer a P. Longás de 16/11/1967.

Gladius, XXVI (2006), pp. 119-147. ISSN: 0435-029X 
Hay que sumar a esta Fototeca especializada el archivo fotográfico personal del matrimonio Hoffmeyer, con anterioridad no integrado oficialmente en la sección y que está formado principalmente por fotografías familiares y álbumes de viaje en diferentes formatos, datados desde finales del siglo XIX hasta los años 80 del siglo XX (Ver Figs. 1 a 5, 11, 14). Esta colección, que sin duda ofrece un gran valor documental por su contribución al conocimiento de la biografía y actividades desarrolladas por el matrimonio, añade aproximadamente otros 2500 originales a los fondos conservados.

El estudio, catalogación y digitalización de las colecciones fotográficas del IEAA constituye una de las principa-

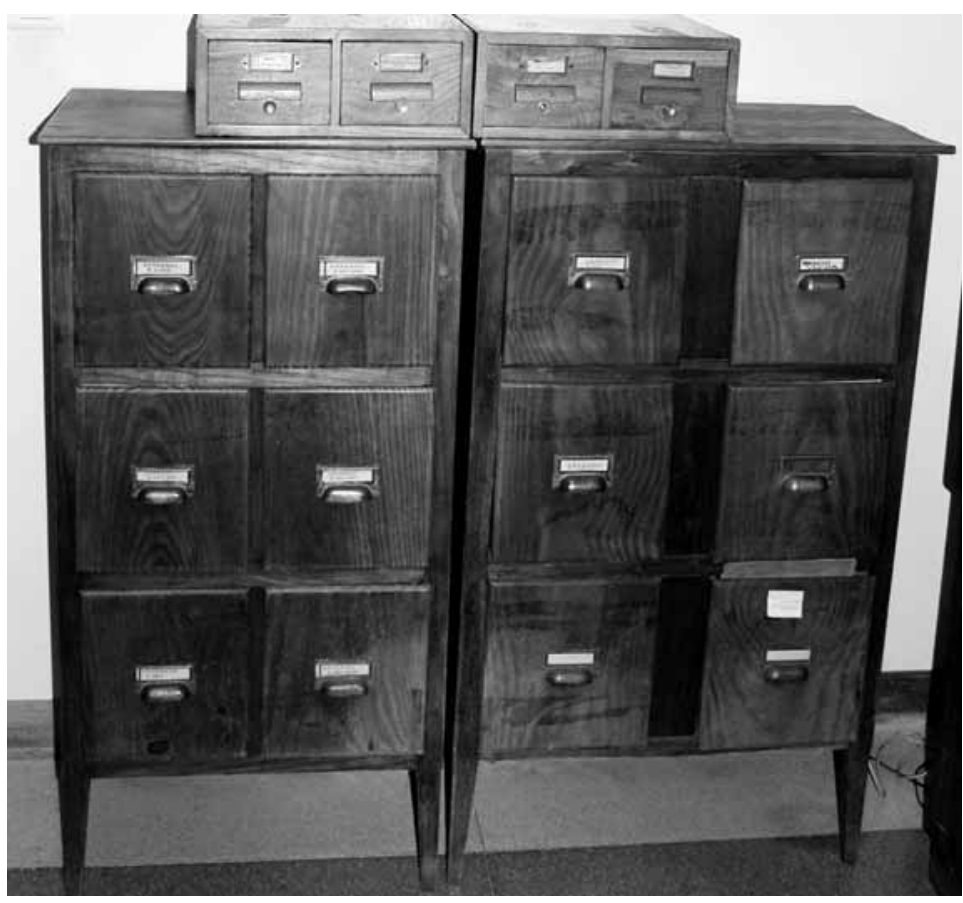

Fig. 17. Detalle de los muebles originales donde se conservan la colección de clichés (inferior), y los ficheros de información sobre las imágenes (superior). Fototeca IHH. Colección Documental. Foto: García Vuelta. les líneas de trabajo que se desarrollan actualmente en el $\mathrm{IHH}^{71}$. El trabajo sobre estos archivos culminará con la creación de una Fototeca Digital en el centro, apoyada en colecciones de imágenes de alta resolución y en un sistema de información que hará posible el acceso a sus contenidos a través de Internet. Está previsto que dicho sistema sea accesible a medio plazo través del web institucional del $\mathrm{IHH}^{72}$.

\section{NOTA FINAL}

Este artículo fue enviado a Gladius en agosto de 2006. Encontrándose el volumen XXVI de la revista en proceso de edición, se ha producido un importante cambio en la adscripción del Instituto Histórico Hoffmeyer, que desde finales de octubre de 2006 es un centro dependiente del Instituto de Arqueología de Mérida (CSIC).

\section{REFERENCIAS}

Colaborador (Anónimo) (1975): «E. Fernando Hoffmeyer (1901-1975)». Gladius XII (1974): 7-12. Bruhn de Hoffmeyer, A. (1985): «El Instituto de Estudios sobre Armas Antiguas. CSIC.». Documento mecanografiado. Agosto de 1985. Archivo del IHH. Sección IEAA.

71 Este proyecto se inició en octubre de 2005 y continúa en el momento actual (García Vuelta, 2006). Hay que señalar finalmente la reciente incorporación a la fototeca de una nueva colección de imágenes relativas al IHH, que pretende ilustrar las actividades desarrolladas en la institución desde 1998, así como documentar los estudios que en ella se realizan actualmente (Ver Figs. 9 y 15-17).

72 http://www.ih.csic.es/presentacion/hoffmeyer 
- (1982): Arms and Armour in Spain. A short survey, II. Instituto de Estudios Sobre Armas Antiguas, CSIC. Madrid.

- (1972): Arms and Armour in Spain. A Short Survey. I. Instituto de Estudios Sobre Armas Antiguas, CSIC. Madrid.

- (1965): Artibus Ingenuis. Roskilde Katedralskole Gennen Tiderne. Roskildenser-Samfundet. Roskilde.

- (1953): «Fordi jeg ikke kunne lade voere». En Einberg, A. (Coord). Saadan Blev Jeg Det. 40 Danske Mend og Kvinder Fortaeller. De Unges Forlag. Copenhague: 51-64.

- (1955): «Ada (Adelheid Maria) Bruhn Hoffmeyer». En: Festskrift udgivet af Københavns Universitet. I Andledning af Universitetets Årsfest. November 1955. Copenhague: 145-147.

- (1954): Middelalderens Tveaeggede Svaerd (2 vols). Tojhusmuseet. Copenhague.

- (1943): Oltos and Early red-figure vase Painting. NYT Nordisk Forlag. Copenhague.

Bruhn DE HoffMeYer, A.; HJorTsø, O. G. (1949): Klassik Kunst. Gyldendalske Boghandel-Nordisk Forlag, Copenhague.

Bruhn de Hoffmeyer, A.; Huortsø, O. G.; Poulsen, V. (1966): Klassisk Kunst. Tekst og Billeder. Gyldendal, Copenhague.

CABrera, P. (1995): «Una nueva cratera de campana del pintor de Lecce». Boletín del Museo Arqueológico Nacional, XIII: 13-19.

CirLot, V. (1980 a): El armamento catalán de los siglos XI al XIV. Tesis Doctoral. Universidad Autónoma de Barcelona.

- (1980 b): «Un modelo de clasificación de la espada. A Propósito de «The Rapier and Small-Sword, 1460-1820», de A.V.B. Norman». Gladius XV: 5-18.

- (1978): «La evolución de la espada en la sociedad catalana de los siglos XI al XIII». Gladius XIV: 9-58.

Cruz Mateos, M. (1998): «Mujeres pioneras de la Arqueología española. Ada Bruhn de Hoffmeyer». Revista de Arqueología 207 (Julio 1998): 42-45.

GABALdón MARTínez, M. P. (2004): Ritos de armas en la Edad del Hierro: armamento y lugares de culto en el antiguo mediterráneo y el mundo celta. Anejos de Gladius 7. CSIC. Madrid.

García-Bellido, M. P. (2004): Las legiones hispánicas en Germania: moneda y ejército. Anejos de Gladius 6. CSIC. Madrid.

- (2006): Los campamentos romanos en Hispania (27 a.C. -192 d. C.). El abastecimiento de moneda. 2 Vols. Anejos de Gladius 9. Madrid.

García Jiménez, G. (2006): Entre Iberos y Celtas. Las espadas de tipo La Tène del Noreste de la Península Ibérica. Anejos de Gladius 10. Madrid.

García Vuelta, O. (2006): «La digitalización de los fondos gráficos del Instituto Histórico Hoffmeyer». La Comarca de la Vera 14: 22.

- (e/p): «Adelheid (Ada) María Bruhn de Hoffmeyer». En Díaz-Andreu, M.; Mora, G. y Cortadella, J. (eds.): Diccionario histórico de la arqueologia en España. Marcial Pons, Madrid. En prensa.

GiBERT, R. (1967): «Gladius, una revista (1961-1966)». Atlántida. Vol. 5, n. ${ }^{\circ}$ 27: 302-304.

HeInBERg, A. (Dir.), (1953): Saadan Blev Jeg Det. 40 Danske Maend og Kvinder fortaeller. Copenhague.

HofFMeYer, E. F. (1974): «Instituto de Estudios sobre Armas Antiguas - Centre International d'Études Supérieures des Armes Anciennes. Memoria 1973». Gladius XI (1973): 138-141.

- (1961): «Córdoba-Toledo-Roma. Contribución Hispano-Árabe a la Cultura Europea». Gladius I: $5-8$.

HofFMeyer, E. F. y BRUHn DE HofFMeyer, A. (1952): Spanien på kryds og tvars: Råd og vink for spaniensrejsende. Copenhague.

Høgsbro, K. E. (2003): «Ada Bruhn Hoffmeyer (1910-1991)». En: Dansk Kvindebiografisk Leksicon. (http: http://www.kvinfo.dk/side/597/bio/317/origin/170/). Acceso Mayo 2006

Instituto De Estudios SOBRE ARMas Antiguas (1973): «Instituto de Estudios sobre Armas Antiguas - Centre International d'Études Supérieures des Armes Anciennes». Gladius X (1972): 120-122.

KAY, E. (Ed.), (1975): «Hoffmeyer, Erling Fernando». En: Men of Achievement. Vol II. Cambrigde: 427.

- (1974): «Bruhn de Hoffmeyer, Ada Maria». En: Dictionary of International Biography. 1975. Vol. 11. Part I. (A-J). Cambrigde - Londres: 245. 
Nicolle, D. (1976): Early medieval islamic arms and armour. Instituto de Estudios sobre Armas Antiguas. CSIC. Madrid.

MarTínez del Peral Fortón, R. (1980): La navaja española antigua. Instituto de Estudios sobre Armas Antiguas. CSIC. Madrid.

Morillo Cerdán, A., (Coord.), (2002): Arqueología militar romana en Hispania. Anejos de Gladius 5. CSIC. Madrid

Sáez AbAD, R. (2005): Artillería y poliocértica en el mundo grecorromano. Anejos de Gladius 8. CSIC. Madrid.

SÁnchez Ocaña FernándeZ, A. (1988): «El instituto de Armología de Jaraíz, 17 años de investigaciones y discreción». Diario HOY (Ed. Extremadura), 9 de mayo de 1988. Cáceres: 11.

SerRadilla MuÑoz, J. V. (1997): «El Instituto de Estudios sobre Armas Antiguas en Jaraíz totalmente restaurado». Diario La Comarca de la Vera, 10 de mayo de 1997: 10-11.

SOLER DEL CAMPO, A.

- (1993): La evolución del armamento medieval en el reino castellano-leonés y Al-andalus (siglos XII-XIV). Serv. Public. del E.M.E. Madrid.

- (1991 a): La evolución del armamento medieval en el reino castellano-leonés y Al-andalus (siglos XII-XIV). Tesis doctoral. Universidad Complutense de Madrid.

- (1991 b): «Dra. Ada Bruhn de Hoffmeyer. Necrológica». Boletín de la Asociación Española de Arqueología Medieval 5: 8-9.

- (1987): El armamento medieval hispano. Madrid.

VV.AA. (1988): «Bruhn Hoffmeyer, Ada». En: Who's who in Europe. Dictionaire biographique des personalités européennes contemporaines. 7. édition (1987-1988). Unión Europea, Waterloo : 364-365.

Recibido: 28/07/2006

Aceptado: 04/09/2006 